\title{
Clientelismo, internet e voto: Personalismo e transferência de recursos nas campanhas online para vereador nas eleições de outubro de 2008 no Brasil
}

\begin{tabular}{c}
\hline \hline Sérgio Braga \\
Departamento de Ciência Política \\
Universidade Federal do Paraná \\
Maria Alejandra Nicolás \\
Doutoranda em Sociologia \\
Universidade Federal do Paraná \\
André Roberto Becher \\
Mestrando em Ciência Política \\
Universidade Federal do Paraná \\
\hline \hline
\end{tabular}

Resumo: $O$ objetivo deste artigo é apresentar os resultados de nossa pesquisa sobre 0 uso da internet pelos candidatos a vereador de Curitiba, Florianópolis e Porto Alegre. A partir do exame da campanha virtual dos candidatos que utilizaram websites entre os cerca de 1400 postulantes aos cargos de vereador nestas capitais, procuramos avaliar o uso que estes políticos fizeram da internet nas eleições municipais de outubro de 2008. Nossa hipótese básica é que as páginas "web" dos candidatos a cargos eletivos, especialmente os vereadores, serviram predominantemente para veicular práticas tradicionais de política, reforçando os vínculos personalistas e clientelistas com o eleitorado.

Palavras-chave: campanha online; clientelismo; internet e política

Abstract: The purpose of this paper is to present the results of our research on Internet using by candidates for councilor in Curitiba, Florianópolis and Porto Alegre. From the examination of virtual campaign of candidates who used websites among about 1.400 applicants for the positions for its offices in these capitals, we evaluate the use of these politicians have made the Internet in municipal elections in October 2008. Our basic hypothesis is that the web pages of candidates for elected office, especially the council, served mainly to disseminate traditional political practices, strengthening personalistic and clientelistic ties with the electorate.

Keywords: online campaign; patronage; internet and politics 
BRAGA, S.; NICOLÁS, M. A.; BECHER, A. R. Clientelismo, internet e voto:...

Introdução ${ }^{1}$

Desde pelo menos meados dos anos 1990 tem havido na literatura internacional um amplo debate sobre a temática da "personalização da política" (MCALlister, 2006; KARVONEN, 2010). Diversos analistas têm detectado o surgimento deste fenômeno mesmo nas democracias mais institucionalizadas e estáveis, o qual manifestar-se-ia nos seguintes níveis ou dimensões da atividade política: i) no nível macroinstitucional e dos processos decisórios mais abrangentes, poderíamos observar um movimento em direção à "presidencialização dos sistemas políticos", com uma tendência à concentração de poderes nas mãos do gabinete ou do chefe do executivo, fenômeno que se manifestaria inclusive nos processos eleitorais, através da posição de predomínio de lideranças políticas carismáticas em escala nacional, que sobrepujariam o papel dos partidos políticos enquanto sinalizadores de policies e agregadores dos interesses das demandas do eleitorado (Mughan, 2000; PogunTKE \& WeBB, 2005); ii) no campo das relações de representação política no sentido estrito do termo, esta tendência à personalização também se manifestaria através de um fortalecimento das funções de constituency service prestadas pelos representantes à sua base eleitoral, com a correlata ostentação da capacidade individual dos representantes de transferir recursos para tais bases, em detrimento de outras funções tradicionalmente desempenhadas pelos membros do parlamento tais como as de divulgar a legenda partidária e/ou posicionar-se em relação a políticas públicas discutidas em nível nacional ou setorial (BLONDEL, 2005); iii) por fim, teríamos uma terceira forma de manifestação da personalização ou individualização das relações políticas estabelecidas pelos diferentes atores do sistema político, que se daria por ocasião da organização das campanhas eleitorais (SWANSON \& MANCINI, 1996). A "personalização", nesse caso específico, ocorreria especialmente por ocasião das campanhas eleitorais, através do emprego cada vez mais maciço de técnicas de marketing político, com o declínio do peso das ideologias veiculadas pelas máquinas partidárias tradicionais nas estratégias de campanha e nas decisões de voto do eleitor, que estaria cada vez mais polarizado pelas características da personalidade do candidato em detrimento do conteúdo substantivo das policies ou de outras formas de identidade coletiva. Uma outra faceta deste fenômeno seria a organização de campanhas eleitorais cada vez mais centradas na personalidade do candidato e no emprego intensivo de técnicas sofisticadas de marketing político voltadas para a construção da imagem do candidato, em detrimento do programa político representado por sua legenda partidária.

Devemos sublinhar, no entanto, dois aspectos importantes: i) mesmo entre analistas que admitem a existência do fenômeno da "personalização", não há consenso se tal fenômeno estaria ou não articulado a uma suposta "crise de representação política" que pretensamente estaria ocorrendo nos sistemas políticos de democracia mais institucionalizada e estável; ii) não há consenso na literatura sobre os impactos de tal fenômeno na qualidade da democracia, ou seja, se o fenômeno da personalização teria efeitos positivos ou não para o aprofundamento da democracia e para o ganho de

\footnotetext{
1 Nota: Esse artigo é uma versão modificada e fundida de trabalhos anteriormente publicados que apresentamos nos $33^{\circ}$ e $36^{\circ}$ Encontro Nacional da Anpocs (BRAGA \& BECHER, 2012; BRAGA, NICOLÁS \& BECHER, 2012). Todos os dados citados abaixo foram produzidos pela equipe de pesquisa do Grupo de Pesquisa Instituições, comportamento político e novas tecnologias, do DECISO/UFPR.
} 
legitimidade de suas decisões junto aos cidadãos. Enquanto alguns autores veem tais processos como intrinsecamente negativos, ao enfraquecer os partidos políticos e os órgãos legislativos no processo decisório global (WEFFORT, 1993, MAINWARING, 1991; AMES, 2003), outros detectam aspectos mais positivos no fenômeno, ao aproximar as lideranças políticas do eleitorado através do emprego de métodos menos burocratizados de representação tornados possíveis especialmente pelas tecnologias digitais (LILLEKER \& JACKSON, 2009; 2011)2.

Com o uso cada vez mais generalizado das novas tecnologias e da internet por várias categorias de atores nas poliarquias contemporâneas - o que levou mesmo alguns analistas a falarem na emergência de um "sistema político virtual" (NORRIS, 2001), já no final do século passado ·, a discussão complexificou-se, na medida em que a internet e as novas tecnologias tiveram forte impacto nos sistemas políticos de vários países, agregando novas dimensões ao funcionamento das poliarquias e ao tipo de relacionamento que ocorre entre elites dirigentes e cidadãos comuns em sua dinâmica de funcionamento. Neste artigo, não abordamos o conjunto desses impactos das Novas Tecnologias da Informação e Comunicação (NTICs) sobre as democracias contemporâneas, mas nos concentramos em apenas uma das dimensões das três mencionadas, qual seja, as formas de manifestação do fenômeno da personalização nas campanhas por ocasião da realização dos pleitos eleitorais, especialmente nas estratégias de comunicação online utilizadas pelos candidatos em nível local.

O objetivo deste artigo é apresentar os resultados de nossa pesquisa sobre o uso da internet pelos candidatos a vereador em Curitiba, Florianópolis e Porto Alegre nas eleições municipais de 2008. A partir do exame da campanha virtual dos 360 candidatos que utilizaram websites entre os 1493 postulantes aos cargos de vereador nestas capitais, procuramos avaliar o uso que estes políticos fizeram da internet. Nossa proposição básica é que as páginas "web" dos candidatos a cargos eletivos, especialmente os vereadores, serviram, predominantemente, para veicular práticas tradicionais de política, reforçando os vínculos personalistas e clientelistas com o eleitorado. Procuramos demonstrar esta hipótese através da construção de alguns indicadores quantitativos e qualitativos de práticas particularistas e clientelistas nos websites dos candidatos a vereador naquelas eleições.

Tendo em vista estes objetivos, o artigo está estruturado em três seções: i) na primeira seção, fazemos a exposição do conceito de clientelismo utilizado, dialogando criticamente com a bibliografia relevante sobre o tema; ii) na segunda seção do artigo, apresentamos os elementos básicos da metodologia utilizada para a análise dos websites dos candidatos a vereador das cidades mencionadas. Procuramos estruturar a análise dos websites dos parlamentares a partir de uma tipologia por nós elaborada para analisar a forma e o conteúdo dos websites; iii) por último, a terceira seção do artigo apresenta os resultados da aplicação de nossa metodologia à analise dos websites dos candidatos a vereador nas eleições municipais de 2008 das capitais supramencionadas e, em seguida, esboça um

\footnotetext{
2 "These MPs will combine a range of functions across most of the variables identified, so presenting themselves as hard-working parliamentarians and constituency servants as well as individuals with a strong sense of personal and political identity. Arguably this can have a positive impact upon political engagement in a number of ways. Such tweets can break down the barriers between representative and the represented, can encourage greater trust and interest and build an impression of the MP that surpasses pejorative media narratives. Equally, it can make the MP appear more accessible, particularly those who not only tweet frequently but also respond to other Twitterers. While in the early phase of usage there may be some electoral benefits. More long term, there may be democratic benefits if MPs and the public begin to listen to one another, correspond, and so adapt the micro-blog platform to incorporate a more participatory platform of engagement" (LILLEKER \& JACKSON , 2011, p. 101).
} 
estudo mais qualitativo dos websites dos postulantes à vereança, empreendendo uma breve análise de conteúdo a fim de ilustrar a maneira como aplicamos nossa tipologia e extrair algumas inferências mais gerais para a análise. Antes de cumprirmos estas metas, apresentamos alguns números preliminares sobre o uso da internet pelos candidatos a vereador no pleito de 2008 nas cidades pesquisadas.

\section{Preliminares: a presença online dos candidatos a vereador na região sul no pleito de outubro de 2008}

A Tabela 1 fornece uma primeira aproximação sobre o uso de websites pelos candidatos a vereador nas três capitais da região sul do país no ano de 2008. Embora, ao contrário do que ocorreu nas eleições majoritárias para prefeitos das capitais, o uso de websites nas eleições proporcionais para vereador, mesmo nas capitais dos estados mais desenvolvidos, não tivesse se tornado um fenômeno amplamente difundido, como poderiam esperar os "cyberotimistas", trata-se de um recurso de campanha em expansão que não pode ser desconsiderado. Esses dados possibilitam uma avaliação empiricamente mais fundamentada do uso de websites pelos candidatos a vereador nas cidades mencionadas e também propiciam uma base para análises longitudinais a serem empreendidas ulteriormente ${ }^{3}$.

Tabela 1

Candidatos a vereador: website versus cidade Eleições Municipais de 2008

\begin{tabular}{|l|c|c|c|c|c|c|}
\hline & \multicolumn{2}{|c|}{ Com website } & \multicolumn{2}{c|}{ Sem website } & \multicolumn{2}{c|}{ Total } \\
\cline { 2 - 7 } & $\mathbf{N}$ & $\%$ & $\mathbf{N}$ & $\%$ & $\mathbf{N}$ & $\%$ \\
\hline Curitiba & 222 & 28,0 & 571 & 72,0 & 793 & 100,0 \\
\hline Florianópolis & 64 & 27,5 & 169 & 72,5 & 233 & 100,0 \\
\hline Porto Alegre & 74 & 15,8 & 393 & 84,2 & 467 & 100,0 \\
\hline Total & 360 & 24,1 & 1133 & 75,9 & 1493 & 100,0 \\
\hline
\end{tabular}

Fonte: Elaboração própria.

Com efeito, observando a Tabela 1, podemos verificar que, dos 1493 candidatos a vereador nas capitais da região sul do país registrados no TSE, cerca de $360(24,1 \%)$ usaram websites para comunicarem-se e interagirem-se com o eleitor. 0 maior percentual de parlamentares com websites foi observado na cidade de Curitiba (28\%), onde também havia um maior número de candidatos (793 no total, contra 469 de Porto Alegre e 233 em Florianópolis).

A distribuição por partidos é informada pela Tabela 2:

\footnotetext{
${ }^{3}$ Os dados foram obtidos nos websites dos partidos políticos, nos T.R.E.s e, principalmente, através da pesquisa direta usando mecanismos de buscas na internet. Não utilizamos os dados do Comitê Gestor da Internet pois verificamos ao longo da investigação que, embora muitos candidatos tivessem registrados domínios terminados em ".can" nestes órgãos, estes domínios não foram colocados no ar ao longo da campanha eleitoral.
} 
OPINIÃO PÚBLICA, Campinas, vol. 19, no 1, junho, 2013, p.168-197

Tabela 2

Candidatos a vereador: website versus partido

Eleições Municipais de 2008

\begin{tabular}{|c|c|c|c|c|c|c|}
\hline & Co & bsite & Sen & bsite & & \\
\hline & $\mathrm{N}$ & $\%$ & $\mathbf{N}$ & $\%$ & $N$ & $\%$ \\
\hline PT & 65 & 58,6 & 46 & 41,4 & 111 & 100,0 \\
\hline PRB & 28 & 54,9 & 23 & 45,1 & 51 & 100,0 \\
\hline$P C$ do $B$ & 18 & 32,1 & 38 & 67,9 & 56 & 100,0 \\
\hline PSDB & 40 & 32,0 & 85 & 68,0 & 125 & 100,0 \\
\hline PPS & 30 & 30,3 & 69 & 69,7 & 99 & 100,0 \\
\hline PP & 26 & 28,0 & 67 & 72,0 & 93 & 100,0 \\
\hline PMDB & 31 & 26,5 & 86 & 73,5 & 117 & 100,0 \\
\hline DEM & 24 & 26,1 & 68 & 73,9 & 92 & 100,0 \\
\hline PV & 20 & 23,0 & 67 & 77,0 & 87 & 100,0 \\
\hline$P R$ & 5 & 17,9 & 23 & 82,1 & 28 & 100,0 \\
\hline PSC & 10 & 16,9 & 49 & 83,1 & 59 & 100,0 \\
\hline PDT & 18 & 15,0 & 102 & 85,0 & 120 & 100,0 \\
\hline PSB & 14 & 12,7 & 96 & 87,3 & 110 & 100,0 \\
\hline PRP & 1 & 12,5 & 7 & 87,5 & 8 & 100,0 \\
\hline PTB & 9 & 12,5 & 63 & 87,5 & 72 & 100,0 \\
\hline PSOL & 7 & 12,3 & 50 & 87,7 & 57 & 100,0 \\
\hline PSDC & 5 & 12,2 & 36 & 87,8 & 41 & 100,0 \\
\hline PMN & 4 & 9,1 & 40 & 90,9 & 44 & 100,0 \\
\hline PRTB & 2 & 8,7 & 21 & 91,3 & 23 & 100,0 \\
\hline PSL & 3 & 6,1 & 46 & 93,9 & 49 & 100,0 \\
\hline PCB & 0 & 0,0 & 3 & 100,0 & 3 & 100,0 \\
\hline PHS & 0 & 0,0 & 17 & 100,0 & 17 & 100,0 \\
\hline PSTU & 0 & 0,0 & 5 & 100,0 & 5 & 100,0 \\
\hline PT do B & 0 & 0,0 & 5 & 100,0 & 5 & 100,0 \\
\hline PTC & 0 & 0,0 & 17 & 100,0 & 17 & 100,0 \\
\hline PTN & 0 & 0,0 & 4 & 100,0 & 4 & 100,0 \\
\hline Total & 360 & 24,1 & 1133 & 75,9 & 1493 & 100,0 \\
\hline
\end{tabular}

Fonte: Elaboração própria.

Das 26 agremiações partidárias que apresentaram candidatos nas cidades mencionadas, o PT foi o partido com maior número de candidatos com websites nas eleições para vereador na região sul do país em outubro de 2008: de seus 111 candidatos a vereador nas três capitais analisadas, 58,6\% disponibilizaram websites pessoais na rede, seguido do pequeno PRB $(54,9 \%)$ e do PCdoB (32,1\%).

Com exceção do PT e do PRB, todos os partidos tiveram menos da metade de seus candidatos usando websites pessoais para se comunicar e interagir com o eleitorado, evidenciando uma vez mais 
que o uso deste recurso ainda é incipiente por parte dos candidatos às eleições proporcionais, mesmo no caso de capitais dos estados desenvolvidos da região sul ${ }^{4}$. Como veremos à frente, entretanto, as diferenças nos tipos de websites entre os dois partidos são significativas, não devendo tais números nos fazer inferir que o uso dos websites por tais agremiações seja semelhante.

Outro dado que devemos analisar, ainda à guisa de apresentação de alguns indicadores preliminares para a análise que faremos a seguir, refere-se à existência de alguma associação entre o uso de websites e a taxa de eleição dos candidatos. A Tabela 3 apresenta os dados oficiais do TSE para agrupar os candidatos ("eleitos", "não eleitos" e "suplentes") e os cruza com o uso ou não-uso de websites na campanha eleitoral:

Tabela 3

Candidatos a vereador: website versus resultado das eleições Eleições municipais de 2008

\begin{tabular}{|l|c|c|c|c|c|c|}
\hline & \multicolumn{2}{|c|}{ Com website } & \multicolumn{2}{c|}{ Sem website } & \multicolumn{2}{c|}{ Total } \\
\hline & $\mathbf{N}$ & $\%$ & $\mathbf{N}$ & $\%$ & N & $\%$ \\
\hline Eleito & 48 & 53,3 & 42 & 46,7 & 90 & 100,0 \\
\hline Não eleito & 28 & 11,8 & 210 & 88,2 & 238 & 100,0 \\
\hline Suplente & 284 & 24,4 & 881 & 75,6 & 1165 & 100,0 \\
\hline Total & 360 & 24,1 & 1133 & 75,9 & 1493 & 100,0 \\
\hline
\end{tabular}

Fonte: Elaboração própria.

Na Tabela 3, é notável a associação entre uso de websites e taxa de sucesso nas eleições: dos 90 candidatos eleitos nas três capitais brasileiras (38 em Curitiba, 16 em Florianópolis e 36 em Porto Alegre), 48 deles (53,3\%) usaram regulamente websites durante a campanha, um grupo bem superior do que os "não-eleitos" (apenas 11,8\%) com website e os "suplentes" (uma percentagem ligeiramente superior de 24,4\%). Assim sendo, o uso de websites é um fator que está associado à competitividade eleitoral, o que podemos considerar como um incentivo para o aumento progressivo observado no uso da "web" pelos candidatos às eleições proporcionais, inclusive na esfera local, nos últimos anos 5 .

Deve-se ter em conta também que, como observam outros estudos, devido aos menores recursos possuídos pelos candidatos à vereança bem como a maior importância dos contatos pessoais e das redes assistencialistas nos pleitos municipais, o recurso à internet por parte dessa categoria de candidatos (especialmente o uso de websites) tende a ser inferior ao observado em outras eleições

\footnotetext{
${ }^{4}$ Devemos observar também algumas características específicas das eleições para vereador em relação às demais, tais como o maior grau de "territorialização" e a maior importância das redes pessoais, que possibilitam o lançamento de um grande número de candidatos "Iaranjas", sem muita competitividade eleitoral, que muitas vezes desempenham o papel de cabos eleitorais para os candidatos a prefeito. Isso, muitas vezes, é responsável pelo superdimensionamento do número e do papel de candidatos pouco competitivos, inflacionando o número de postulantes formais (sem reais chances de eleição e muitos casos sem efetivamente realizar campanhas eleitorais) ao posto (Cf. Brandão e Batista (2008)). Sublinhe-se também que, embora a legislação em vigor estabelecesse uma série de restrições à campanha em blogs de terceiros e mídias sociais, o uso de tais recursos era facultado aos candidatos desde que hospedados em seus websites, pelo que o baixo grau e as características de uso da web no pleito examinado não podem ser imputadas apenas às interdições legais.

${ }^{5}$ Segundo os dados do estudo de Brandão e Batista (2008), o uso da internet tem crescido regularmente nas eleições brasileiras, mesmo antes dos impactos do "efeito Obama", quando os potenciais mobilizadores da internet tornaram-se mais ou menos evidentes para todos os observadores políticos: embora não incluam os vereadores em seu levantamento, os autores detectam os seguintes percentuais de candidatos "digitalmente incluídos" e com websites registrados no Comitê Gestor da Internet no Brasil nas eleições brasileiras anteriores ao pleito municipal de outubro de 2008: Presidente da República (62,5\% dos candidatos); governador de estado (43,0\%); senadores (28,8\%); deputado federal (12,1\%), sendo que estas duas últimas categorias registram um percentual já inferior ao observado anteriormente nas eleições para vereador, indicando a acelerada progressão no uso da internet de eleição para eleição.
} 
proporcionais tais como as de deputado federal e estadual ou, como é mais evidente, para as eleições majoritárias, onde o uso da internet tende a ser mais frequente, mesmo considerando que este ainda esteja embrionário nas eleições brasileiras (BRANDÃo e BATISTA, 2008).

Entretanto, se notamos uma considerável progressão no uso da internet pelos candidatos nas eleições majoritárias e proporcionais, inclusive em nível municipal, que só tende a aumentar nos próximos pleitos, a questão mais relevante que devemos colocar é: de que forma este recurso tem sido utilizado pelos candidatos? Que tipo de uso da internet podemos observar nos pleitos eleitorais brasileiros e que tipo de relação os candidatos buscam estabelecer com os eleitores a partir de seus websites?

Procuramos responder a estas indagações através de uma análise de conteúdo dos websites dos vereadores "digitalmente incluídos". Enfatize-se desde logo, portanto, que o objetivo precípuo deste artigo não é analisar a internet sob a "ótica da demanda”, ou seja, avaliar qual a sua eficácia efetiva para angariar votos e como instrumento ou recurso de mobilização e propaganda eleitorais, mas sim da "ótica da oferta", ou seja, como os candidatos efetivamente usaram a internet para veicular suas mensagens no pleito de $2008^{6}$.

Como afirmamos, nossa hipótese é que as páginas "web" dos candidatos a cargos eletivos, especialmente os vereadores, serviram predominantemente para veicular práticas tradicionais de política, reforçando os vínculos personalistas, assistencialistas e "clientelistas" com o eleitorado, em detrimento de campanhas virtuais que promovessem uma maior politização, participação e interação com os cidadãos, ou a criação de efetivos espaços discursivos para os eleitores. Entretanto, deve ser sublinhado que esse padrão dominante de websites não esgotou todas as possibilidades de uso da internet pelos candidatos à vereança no último pleito: embora minoritários em relação ao padrão dominante, detectamos alguns padrões discrepantes e usos mais participativos da internet nas eleições municipais de 2008 que podem antecipar novas tendências de uso da "web" a serem consolidadas nos próximos pleitos.

Procuramos demonstrar essas proposições através da construção de alguns indicadores quantitativos e qualitativos de práticas assistenciais e clientelistas nos websites dos candidatos a prefeito e vereadores. Assim, nosso primeiro passo neste artigo é apresentar as definições de "clientelismo", "personalismo" e "assistencialismo", bem como a metodologia para averiguar a presença de tais práticas políticas nos websites dos candidatos à vereança nas eleições proporcionais nas capitais analisadas.

Com efeito, embora já exista uma ampla bibliografia sobre o tema do clientelismo no Brasil, nem sempre são claros os conceitos empregados por cada analista e as formas pelas quais eles podem ser operacionalizados na análise política. Embora estudos anteriores sobre o uso da internet nas eleições tenham tangenciado o tema do clientelismo (OLIVEIRA et al, 2008), o tema é tratado de maneira apenas

\footnotetext{
${ }^{6}$ Por questões de economia de exposição, não faremos um balanço da ampla literatura existente sobre "internet e eleições" no exterior e no Brasil. Como demonstram inventários mais recentes, as análises sobre o assunto no estrangeiro seguiram sucessivas "ondas", conforme o tipo de emprego da tecnologia e os potenciais mobilizadores das mesmas (GomES e AGGIO, 2009; AgGIO, 2010). No tocante ao Brasil, pelo menos no campo da Ciência Política, os estudos ainda são embrionários, destacando-se o trabalho de Brandão e Batista (2008) anteriormente mencionado, o monitoramento efetuado por Fernandez a partir da aplicação do modelo de Ward e Gibson nos pleitos majoritários brasileiros (FERNANDEZ, 2005; IASULAITIS, 2007), e a breve tentativa de elaborar um perfil dos usuários e não usuários no pleito de outubro de 2006 empreendida por Braga et al (2007).
} 
marginal, não se definindo nenhuma metodologia sistemática de análise que trate especificamente do assunto, muito menos buscando-se analisar um grande número de candidatos de maneira comparada. Por outro lado, geralmente, a internet tem sido analisada por instaurar formas mais avançadas de democracia, não se examinando as possibilidades da "web" como um veículo condutor de manifestações de formas tidas como "arcaicas" de atividade política, como procuramos fazer neste artigo.

Nas próximas seções, buscamos avançar na abordagem destas questões, a partir do seguinte plano: i) inicialmente, apresentamos brevemente o conceito de clientelismo que utilizamos em nossa abordagem a partir do diálogo com alguns textos que consideramos de fundamental importância para o entendimento do fenômeno; ii) em seguida, apresentamos os aspectos básicos de nossa metodologia de content analysis dos websites dos candidatos desdobrando-a em duas dimensões: a) a forma dos websites e b) seu conteúdo; iii) na terceira seção do artigo, aplicamos tal metodologia à análise dos websites das capitais brasileiras da região sul.

A ideia subjacente a este artigo é a da existência de diferentes modalidades de representação política que podem ser expressas pelas plataformas virtuais dos candidatos, a partir das quais é possível apreender os diferentes modelos e graus de representação estabelecidos entre políticos e eleitores (NORTON, 2007; LILLEKER \& JACKSON, 2009; NICOLÁS, 2009).

\section{Conceito de clientelismo e metodologia de análise}

A primeira questão que devemos responder é como conceituar "clientelismo" e como examinar suas formas de manifestação nos websites dos candidatos à vereança nas eleições examinadas ${ }^{7}$.

Não cabe aqui, naturalmente, entrar no amplo debate travado na literatura sobre o conceito de clientelismo e seus correlatos ${ }^{8}$. Cabe apenas mencionar que, quaisquer que sejam as variações de abordagem do assunto, geralmente dois pontos comuns são enfatizados pelas diferentes abordagens: i) o "clientelismo" envolve uma relação de troca ou permuta entre o "patrão" ou o "político" (no nosso caso, os candidatos à vereança) e seu "cliente" (eleitor potencial ou real) baseada em uma transferência de recursos daqueles para estes últimos; ii) o clientelismo envolve uma relação durável de natureza assistencial e personalizada entre um "político" ou liderança política, e sua "clientela" (real ou potencial) qualquer que seja a dimensão em que esta ação se dê (campanha eleitoral, exercício do mandato, execução de políticas governamentais etc.), estabelecendo-se, portanto, uma relação assimétrica de barganha mútua (ou de "troca", para os adeptos de um viés mais antropologizante) entre as partes.

Tendo em vista esses aspectos comuns, podemos detectar uma dupla vertente de conceituação do fenômeno na literatura: a) aquela vertente para a qual o clientelismo é um resquício de sociedades tradicionais ou pré-modernas, aparentado a outros fenômenos políticos tais como "coronelismo", "mandonismo" ou a sobrevivência de oligarquias pré-modernas, incompatível com o "universalismo de procedimentos" e cuja presença evidencia problemas de funcionamento nas democracias parlamentares (NUNES, 1997); b) aquela vertente para a qual o fenômeno do clientelismo pode ser considerado também um fenômeno "moderno" e plenamente compatível com a dinâmica de funcionamento das democracias

\footnotetext{
7 Para simplificar a exposição - e dado que nosso objetivo central neste artigo é propor uma metodologia de análise da forma e do conteúdo dos websites que permita verificar a presença de tal fenômeno na web - abordamos conjuntamente fenômenos políticos correlatos tais como "clientelismo", "personalismo" e "assistencialismo".

8 Para algumas tentativas mais recentes de balanço do tema, ver Carvalho (1997), Kuschnir et al (2005) e Veloso (2006).
} 
parlamentares institucionalizadas em suas múltiplas dimensões (organização do processo eleitoral; processo decisório e legislativo; execução das políticas governamentais) (AVELINO, 1994; FARIAS, 2000) ${ }^{9}$.

Neste artigo, seguindo a vertente de análise inaugurada por estes últimos autores, utilizamos a expressão "clientelismo" para designar fenômenos políticos bastante distintos de práticas políticas prémodernas tais como o "coronelismo" ou o "mandonismo" dos notáveis, supostamente incompatíveis com o universalismo de procedimentos ou com a concepção moderna de cidadania. Nesse sentido, utilizamos a expressão clientelismo como um fenômeno político amplamente compatível com o funcionamento estável e "normal" de uma democracia parlamentar institucionalizada, podendo mesmo sobreviver e/ou se reforçar a partir dos impactos das NTICs nos sistemas políticos contemporâneos, o mesmo ocorrendo com o fenômeno do personalismo na organização das campanhas eleitorais.

A partir desse debate, esboçamos uma definição estritamente instrumental de "clientelismo", necessária à definição de uma metodologia de content analysis dos websites examinados e à demonstração de algumas das proposições básicas de nosso enfoque. O ponto de partida de nossa abordagem é a seguinte definição ampla e genérica de clientelismo: o tipo de relação assimétrica que se estabelece entre uma liderança política (seja um candidato a cargo eletivo, um político em exercício do mandato, um ocupante de cargo executivo ou mesmo um burocrata nomeado) e os membros comuns de uma determinada coletividade (eleitores reais ou potenciais, "cabos eleitorais" e outros atores que estão na "base da pirâmide" dessa relação) onde vínculos personalistas baseados na prestação de serviços, assistência pessoal e transferência concentrada de recursos em troca de votos predominam sobre outros vínculos, tais como a identificação simbólico-programática com uma legenda ou rótulo partidário ou a demanda de uma determinada constituency ou grupos de interesse organizados por políticas de governo de maior impacto alocativo.

Nesse sentido, o clientelismo pode ser caracterizado como uma relação de dupla face: pelo lado do político ou broker (AVELINO, 1994), temos a ostentação de sua capacidade de transferir recursos materiais ou simbólicos para uma determinada localidade a partir de sua relação ou de seu acesso privilegiado com a administração pública ou a determinados recursos políticos; por parte do eleitor ou do cidadão comum, temos a contrapartida de submeter-se a essa relação, aceitando os termos da troca que Ihe são propostos, e votando ou prestando apoio a determinado líder político em troca de tais benefícios particularistas a partir de uma visão estritamente instrumental e utilitária dos resultados do processo político. Benefícios particularistas estes que se sobrepõem a outros, talvez menos tangíveis, tais como o fortalecimento numérico e organizacional de uma determinada agremiação partidária, o crescimento e o aumento do prestígio ou visibilidade de determinadas associações civis e corporativas, e/ou a execução de determinadas políticas governamentais de maior impacto alocativo ("políticas públicas") para a coletividade de referência mais ampla dentro das quais os cidadãos se inserem ${ }^{10}$.

\footnotetext{
${ }^{9}$ Avelino (1994) estabelece uma distinção entre o "clientelismo antigo", baseado em vínculos de natureza pré-moderna e o "clientelismo moderno", compatível com a lógica das poliarquias. Farias (2000) estabelece uma distinção entre "clientelismo privado" e o "clientelismo estatal" emergente a partir do declínio dos pequenos líderes locais. Segundo Avelino: "A política clientelista "moderna" é mais competitiva que sua antecessora e suas relações tendem a ser muito mais frágeis, já que mais "instrumentais". Ela sobrevive a partir da sua capacidade de substituir os antigos laços de lealdade pessoal pela oferta de benefícios materiais, os mais individuais possíveis, de maneira a evitar conflitos e maximizar o seu arco de influência eleitoral. 0 patrono moderno é o broker. E seu poder depende das suas habilidades em operar como intermediário entre sua clientela e os recursos públicos" (AvELINO, 1994, p. 227).

10 Sublinhe-se novamente que, definido dessa forma, longe de ser uma reminiscência ou herança de "sociedades pré-modernas", o clientelismo pode ser considerado um fenômeno amplamente difundido inclusive em sociedades capitalistas avançadas,
} 
Em resumo, definimos o clientelismo como a ostentação da capacidade do político de promover a transferência de recursos, execução de obras específicas para determinadas comunidades ou segmentos da sociedade, a partir de sua prerrogativa de agir como um "agente de intermediação" com a administração pública. Uma forma de manifestação deste tipo de atividade política ocorre quando o político ostenta na campanha eleitoral sua prerrogativa de agir como um "despachante de luxo" (palavras geralmente empregadas pelos próprios atores envolvidos nesta relação) de determinada comunidade ou segmento social, em troca do voto dado pelo eleitor.

Sublinhe-se que essa relação de "clientela", embora deva ter durabilidade no tempo para se institucionalizar, já começa a se manifestar a partir do momento da eleição e da organização das campanhas eleitorais (ex-ante) e não apenas ex-post por ocasião da posse do político no exercício do mandato ou do cargo público de uma maneira geral.

Para os fins deste artigo, entretanto, o mais importante é definir uma metodologia de análise dos websites de campanha eleitoral de candidatos a vereador que nos permita apreender estes fenômenos. Nesse sentido, partimos da proposição segundo a qual existem quatro níveis onde o clientelismo e as políticas particularistas manifestam-se ou podem manifestar-se na organização de uma campanha eleitoral por intermédio de websites legislativos:

1) Na forma ou característica dominante dos websites (ênfase na exposição estática da personalidade do candidato e em sua capacidade de executar obras ou transferir recursos para uma coletividade, bairro ou segmento social específico, em detrimento da ostentação dos vínculos partidários, de seus laços com movimentos reivindicatórios ou do uso de recursos que permitam uma maior participação e interpelação dos cidadãos a respeito da natureza substantiva de suas policies);

2) No que se refere ao conteúdo das políticas propostas, ou seja, se há indícios ou evidências de que políticas de menor impacto alocativo e mais voltadas para a transferência de recursos para determinadas localidades (pork barre) estão sendo veiculadas pelos websites;

3) Quanto às funções desempenhadas pelos websites no sentido de servir como instrumento de organização e estruturação de diferentes graus ou modelos de representação política dos cidadãos pelas elites políticas (NORTON, 2007; LILLEKER \& JACKSON, 2009) ${ }^{11}$.

especialmente naquelas regiões ou segmentos do eleitorado onde, por motivos diversos, o grau de consciência cívica dos indivíduos não se orienta no sentido de eleger lideranças mobilizadas em torno de plataformas programáticas e programas de governo ou de mais abrangentes e/ou de maior apelo simbólico e impacto alocativo setorial ou geral.

11 Norton (2007), por exemplo, identifica quatro modelos de representação política em seu estudo da internet pelos MPs no Parlamento britânico: i) o modelo tradicional, que se caracteriza por rejeitar o uso das NTICs como um meio de reforçar os modos ou relações de representação. Este modelo pode ser testado através do número de parlamentares com e-mails e websites. Embora o uso dessas ferramentas esteja generalizado entre os parlamentares, não são todos os que as utilizam. Isso pode ser consequência da falta de conhecimento sobre a tecnologia, falta de funcionários especializados ou por desinteresse pessoal. Deve-se mencionar ainda que aqueles que utilizam e-mail e website não são plenamente conscientes dos potenciais da internet. Neste modelo, os cidadãos são vistos como excluídos, já que não têm formas de contato; ii) o modelo partidário, que se caracteriza por enfatizar a posição dominante do partido e que pode ser observado principalmente através do uso que os deputados fazem de seus websites. Neste modelo, a internet é usada para assegurar que as mensagens do partido sejam transmitidas eletronicamente. A comunicação entre os parlamentares e os cidadãos espelha a comunicação tradicional, na qual reforça-se a posição do partido ou esta não é desafiada e os cidadãos são essencialmente passivos, sendo recipientes de material disponibilizado pela internet. A comunicação é primária, embora não exclusivamente de uma só via (monodirecional); iii) o modelo representativo se caracteriza pelo emprego da internet como uma ferramenta de disseminação das posturas dos parlamentares sobre diversos temas, possibilitando a eles atuarem como entidades independentes ou menos dependentes do partido. O modelo representativo pode ser testado principalmente através do uso que os deputados fazem de seus websites. A internet não é empregada para reforçar os meios de comunicação existentes, mas sim para criar novos desafios que possibilitarão ao parlamentar ignorar o partido. Neste modelo, os cidadãos são vistos essencialmente como reativos - tendo alguns engajamentos com os parlamentares; iv) por fim, podemos detectar o "modelo de tribuna" (delegativo) que enfatiza o uso das NTICs para recolher as posturas dos eleitores de uma maneira que os modos de comunicação tradicionais não permitem. 
4) Por intermédio do "discurso" ou do conteúdo substantivo das mensagens difundidas pelos websites.

Nesse sentido, podemos definir uma metodologia que apreenda essas formas de manifestação nos seguintes níveis ou momentos de análise: 1) Em primeiro lugar, a caracterização dos websites quanto à sua forma e ao seu conteúdo; 2) Em segundo lugar, aplicação adaptada do modelo de Lilliker acerca das funções desempenhadas pelos websites dos candidatos em sua relação com o eleitorado, visando a mensuração das variáveis anteriormente mencionadas. Entretanto, por questões de espaço, essa dimensão de análise não será exposta aqui; 3) E, por fim, análise qualitativa dos websites, a fim de verificar o tipo de conteúdo substantivo que é veiculado por cada website no período da campanha eleitoral.

Nos próximos itens, expomos os resultados da pesquisa na primeira e na terceira destas formas de manifestação das mensagens políticas.

\section{Análise dos dados: a forma e o conteúdo dos websites dos candidatos a vereador no Brasil Meridional (Curitiba, Florianópolis e Porto Alegre).}

No que se refere à forma e ao conteúdo dos sites dos candidatos, definimos a seguinte tipologia que aplicamos à análise dos sites:

a) quanto à forma ou à característica predominante do website parlamentar, utilizamos uma tipologia com quatro tipos básicos de websites: 1) "outdoor virtual personalizado" (i. e., quando o site do candidato é focado predominantemente na personalidade e nas realizações pessoais do candidato, assim como na "conexão eleitoral" por ele estabelecida com o eleitor potencial); 2) "outdoor virtual partidarizado" (mesmo tipo que o anterior, mas com maior ênfase nas políticas e no rótulo partidário); 3) ênfase nas atividades parlamentares (caso em que as ferramentas da web são usadas predominantemente para divulgar as atividades parlamentares do candidato); 4) comunicação e interação (quando os websites dos políticos apresentam mais recursos para se comunicar e interagir com o eleitor, tais como newsletter, boletins informativos, vídeos e outros recursos de comunicação); e 5) “candidatos web 2.0", que são aqueles que usam websites nos quais estão presentes ferramentas de interação mais avançadas e que permitem uma maior participação dos cidadãos no processo deliberativo referente à ação política das lideranças e maior acesso à informação mediante plataformas multimídia, tais como redes sociais, plataformas interativas etc.;

b) no tocante ao conteúdo dos websites, definimos os seguintes tipos básicos: 1) ênfase na capacidade do político de transferir recursos ou executar serviços e obras para uma determinada localidade ou determinado grupo específico; 2) ênfase em políticas de governo e em propostas gerais do partido ou na atividade parlamentar; 3) ênfase em vínculos com movimentos e setores organizados, tais como: empresários, movimentos sociais, sindicatos, movimentos estudantis, categorias profissionais etc.; 4) ênfase em maior politização e densidade programática com problematização de aspectos ideológicos-programáticos mais gerais e substantivos debatidos pela coletividade de referência do líder político.

Nesse modelo, a internet oferece a oportunidade de estruturar formas de interação mais diretas entre os parlamentares e os eleitores. Em tal ambiente interativo, os parlamentares têm a facilidade de responder e explicar suas ações e comentários e o papel dos cidadãos é visto com sendo ativo. Cf. a respeito Norton (2007) e Nicolás (2009, p. 43 e segs.). 
As frequências foram obtidas da seguinte forma: após treinamento prévio, dois membros de nosso grupo de pesquisa classificavam os websites mediante uma inspeção visual abrangente. Em caso de divergência, o coordenador da pesquisa desempatava a escolha.

Quanto à forma dos websites, os principais dados que coletamos ${ }^{12}$ encontram-se expostos na Tabela 4:

Tabela 4

Candidatos a vereador: forma do website versus município Eleições municipais de 2008

\begin{tabular}{|l|c|c|c|c|c|c|c|c|}
\hline \multirow{2}{*}{} & \multicolumn{2}{|c|}{ Curitiba } & \multicolumn{2}{c|}{ Florianópolis } & \multicolumn{2}{c|}{ Porto Alegre } & \multicolumn{2}{c|}{ Total } \\
\cline { 2 - 10 } & $\mathrm{N}$ & $\%$ & $\mathrm{~N}$ & $\%$ & $\mathrm{~N}$ & $\%$ & $\mathrm{~N}$ & $\%$ \\
\hline Outdoor personalizado & 104 & 64,2 & 35 & 62,5 & 32 & 51,6 & 171 & 61,1 \\
\hline Outdoor partidarizado & 35 & 21,6 & 6 & 10,7 & 7 & 11,3 & 48 & 17,1 \\
\hline Gabinete virtual & 7 & 4,3 & 11 & 19,6 & 9 & 14,5 & 27 & 9,6 \\
\hline Comunicação e informação & 16 & 9,9 & 4 & 7,1 & 14 & 22,6 & 34 & 12,1 \\
\hline Total & 162 & 100,0 & 56 & 100,0 & 62 & 100,0 & 280 & 100,0 \\
\hline
\end{tabular}

Fonte: Elaboração própria.

A Tabela 4 nos permite apresentar uma primeira evidência do predomínio de práticas clientelistas nos websites dos candidatos e políticos analisados. Com efeito, do total de 280 websites examinados, 171 (61,1\%) apresentaram características predominantes de "outdoor personalizado", sendo que os maiores e menores percentuais foram detectados, respectivamente, em Curitiba $(64,2 \%)$ e Porto Alegre $(51,6 \%)$. Esses dados, de certa forma, corroboram a percepção corrente de Porto Alegre como sendo uma capital mais politizada, onde os partidos de esquerda e direita são mais institucionalizados.

No tocante às relações entre forma do website e legenda partidária, os dados encontram-se expostos na Tabela 5:

\footnotetext{
12 Do total de 360 candidatos que efetivamente usaram websites durante a campanha eleitoral, e não apenas registraram o domínio.can no registro.com, conseguimos concluir a análise de conteúdo de 280 deles, que constituem a amostra para a análise deste artigo.
} 
OPINIÃO PÚBLICA, Campinas, vol. 19, no 1, junho, 2013, p.168-197

Tabela 5

Candidatos a vereador: forma do website versus partido Eleições Municipais de 2008

\begin{tabular}{|c|c|c|c|c|c|c|c|c|c|c|}
\hline & \multicolumn{2}{|c|}{$\begin{array}{c}\text { Outdoor virtual } \\
\text { personalizado }\end{array}$} & \multicolumn{2}{|c|}{$\begin{array}{c}\text { Outdoor virtual } \\
\text { partidarizado }\end{array}$} & \multicolumn{2}{|c|}{ Gabinete virtual } & \multicolumn{2}{c|}{$\begin{array}{c}\text { Comunicação e } \\
\text { interação }\end{array}$} & \multicolumn{4}{c|}{ Total } \\
\hline & $\mathrm{N}$ & $\%$ & $\mathrm{~N}$ & $\%$ & $\mathrm{~N}$ & $\%$ & $\mathrm{~N}$ & $\%$ & $\mathrm{~N}$ & $\%$ \\
\hline PR & 4 & 100,0 & 0 & 0,0 & 0 & 0,0 & 0 & 0,0 & 4 & 100,0 \\
\hline PTB & 6 & 100,0 & 0 & 0,0 & 0 & 0,0 & 0 & 0,0 & 6 & 100,0 \\
\hline ppd & 32 & 94,1 & 1 & 2,9 & 1 & 2,9 & 0 & 0,0 & 34 & 100,0 \\
\hline DEM & 15 & 83,3 & 1 & 5,6 & 2 & 11,1 & 0 & 0,0 & 18 & 100,0 \\
\hline PP & 15 & 78,9 & 0 & 0,0 & 1 & 5,3 & 3 & 15,8 & 19 & 100,0 \\
\hline PMDB & 17 & 77,3 & 3 & 13,6 & 1 & 4,5 & 1 & 4,5 & 22 & 100,0 \\
\hline PSB & 10 & 71,4 & 0 & 0,0 & 2 & 14,3 & 2 & 14,3 & 14 & 100,0 \\
\hline PSDB & 25 & 71,4 & 0 & 0,0 & 4 & 11,4 & 6 & 17,1 & 35 & 100,0 \\
\hline PPS & 16 & 64,0 & 5 & 20,0 & 2 & 8,0 & 2 & 8,0 & 25 & 100,0 \\
\hline PDT & 6 & 54,5 & 2 & 18,2 & 1 & 9,1 & 2 & 18,2 & 11 & 100,0 \\
\hline Ppe & 10 & 43,5 & 4 & 17,4 & 5 & 21,7 & 4 & 17,4 & 23 & 100,0 \\
\hline PV & 6 & 37,5 & 4 & 25,0 & 1 & 6,3 & 5 & 31,3 & 16 & 100,0 \\
\hline PT & 9 & 17,0 & 28 & 52,8 & 7 & 13,2 & 9 & 17,0 & 53 & 100,0 \\
\hline Total & 171 & 61,1 & 48 & 17,1 & 27 & 9,6 & 34 & 12,1 & 280 & 100,0 \\
\hline
\end{tabular}

Fonte: Elaboração própria.

A Tabela 5 mostra que as características predominantes dos websites encontram-se distribuídas de forma bastante desigual pelos diferentes partidos políticos. Partidos como DEM, PMDB, PP, PR, PTB e "ppd" (pequenos partidos de direita) apresentam todos um alto percentual de websites do tipo "outdoor pessoal”. Em seguida, há um segundo grupo integrado por PDT, PPS, PSB, PSDB, onde há um predomínio de websites do tipo "outdoor personalizado", mas em proporção menor do que a existente no grupo anterior. E, por fim, um terceiro grupo de partidos onde o percentual de websites com esta característica predominante é inferior em relação aos demais, tais como os "ppe" (pequenos partidos de esquerda), PT e PV, agremiações que por esse motivo fazem uso dos websites centrados menos na personalidade dos candidatos e mais nas legendas das agremiações.

Destaque-se a esse respeito o $\mathrm{PV}$, que pode ser definido como o partido com maior frequência de candidatos "Comunicação e Participação"13, com sites onde estão presentes maiores recursos para interação e comunicação com o cidadão-internauta.

A relação entre a forma do website e o resultado eleitoral, por sua vez, é indicada na Tabela 6:

\footnotetext{
${ }^{13}$ Em nossa pesquisa, não encontramos nenhum website que pudesse ser considerado "Web 2.0", com recursos mais avançados de interação com o eleitor e que funcionasse como uma plataforma de constituição da redes sociais e de ampliação da participação política. Por outro lado, quando o partido ofereceu ao candidato um "template" de site que destacasse a legenda partidária, mas sem recursos de interação mais avançados, incluímos este tipo de website na categoria de "outdoor partidário".
} 
BRAGA, S.; NICOLÁS, M. A.; BECHER, A. R. Clientelismo, internet e voto:...

Tabela 6

Candidatos a vereador: forma do website versus taxa de eleição Eleições Municipais de 2008

\begin{tabular}{|l|c|c|c|c|c|c|}
\hline \multirow{2}{*}{} & \multicolumn{2}{|c|}{ Eleito } & \multicolumn{2}{c|}{ Não Eleito } & \multicolumn{2}{c|}{ Total } \\
\cline { 2 - 7 } & $\mathrm{N}$ & $\%$ & $\mathrm{~N}$ & $\%$ & $\mathrm{~N}$ & $\%$ \\
\hline Outdoor personalizado & 24 & 60,0 & 147 & 61,3 & 171 & 61,1 \\
\hline Outdoor partidarizado & 3 & 7,5 & 45 & 18,8 & 48 & 17,1 \\
\hline Gabinete virtual & 3 & 7,5 & 24 & 10,0 & 27 & 9,6 \\
\hline Comunicação e interação & 10 & 25,0 & 24 & 10,0 & 34 & 12,1 \\
\hline Total & 40 & 100,0 & 240 & 100,0 & 280 & 100,0 \\
\hline
\end{tabular}

Fonte: Elaboração própria.

Os dados da Tabela 6 mostram que o percentual de eleitos e não-eleitos que utilizaram websites do tipo "outdoor virtual" é quase o mesmo. Deste modo, parece não haver associação entre a forma de website e o grau de sucesso eleitoral dos candidatos a cargo eletivo. Por outro lado, também é elevado o percentual de eleitos que utilizaram predominantemente websites do tipo "Comunicação e informação" 14 , com recursos de comunicação mais sofisticados, demonstrando haver um significativo espaço de atuação para candidatos mais preocupados em utilizar ferramentas mais modernas de interação propiciadas pela Rede.

No tocante ao conteúdo das políticas divulgadas pelos websites, os dados estão sintetizados na Tabela 7:

Tabela 7

Candidatos a vereador: conteúdo do website versus cidade Eleições Municipais de 2008

\begin{tabular}{|c|c|c|c|c|c|c|c|c|}
\hline & \multicolumn{2}{|c|}{ Curitiba } & \multicolumn{2}{|c|}{ Florianópolis } & \multicolumn{2}{|c|}{ Porto Alegre } & \multicolumn{2}{|c|}{ Total } \\
\hline & $\mathrm{N}$ & $\%$ & $\mathrm{~N}$ & $\%$ & $\mathrm{~N}$ & $\%$ & $\mathrm{~N}$ & $\%$ \\
\hline Transferência de recursos & 84 & 51,9 & 29 & 51,8 & 29 & 46,8 & 142 & 50,7 \\
\hline Partido e atividade parlamentar & 59 & 36,4 & 23 & 41,1 & 18 & 29,0 & 100 & 35,7 \\
\hline Vínculos com grupos & 15 & 9,3 & 4 & 7,1 & 14 & 22,6 & 33 & 11,8 \\
\hline Densidade programática & 4 & 2,5 & 0 & 0,0 & 1 & 1,6 & 5 & 1,8 \\
\hline Total & 162 & 100,0 & 56 & 100,0 & 62 & 100,0 & 280 & 100,0 \\
\hline
\end{tabular}

A Tabela 7 mostra que, em todas as cidades pesquisadas, é predominante a ênfase na capacidade dos candidatos em transferirem recursos para determinada base ou região eleitoral, embora esse percentual seja menos intenso do que o verificado no uso de website personalizado. Destaca-se uma

\footnotetext{
${ }^{14} \mathrm{Em}$ nossa pesquisa com os candidatos a vereador em outubro de 2008 , ao contrário do que ocorreu com a pesquisa feita nos websites dos candidatos a prefeito das capitais e principais cidades brasileiras, não encontramos nenhum candidato que pudesse ser considerado "web 2.0", com recursos mais avançados de interação com o eleitor e usasse seu website como uma plataforma de constituição de redes sociais e de mobilização dos cidadãos a partir da possibilidade de postagem de conteúdos produzidos pelos militantes. Na realidade, os espaços para a manifestação de "falas cidadãs" nos websites dos candidatos às eleições de 2008 , tanto às prefeituras como a vereador foram bastante reduzidos. A respeito do conceito de "falas cidadãs", ver a sugestiva análise de Blanchard sobre os partidos políticos franceses (BLANCHARD, 2006).
} 
vez mais o caso de Porto Alegre, com forte percentual de candidatos enfatizando predominantemente o rótulo partidário e a atividade parlamentar (29\%), assim como o vínculo com grupos e segmentos sociais mais organizados $(22,6 \%)$.

No tocante aos partidos políticos mais relevantes, os percentuais estão expressos na Tabela 8:

Tabela 8

Candidatos a vereador: conteúdo do website versus partido Eleições municipais de 2008

\begin{tabular}{|c|c|c|c|c|c|c|c|c|c|c|}
\hline & \multicolumn{2}{|c|}{$\begin{array}{c}\text { Transferência } \\
\text { concentrada de } \\
\text { recursos }\end{array}$} & \multicolumn{2}{|c|}{$\begin{array}{l}\text { Propostas do } \\
\text { partido e } \\
\text { parlamento }\end{array}$} & \multicolumn{2}{|c|}{$\begin{array}{l}\text { Vínculos com } \\
\text { setores } \\
\text { organizados }\end{array}$} & \multicolumn{2}{|c|}{$\begin{array}{c}\text { Densidade } \\
\text { programática e } \\
\text { apelo simbólico }\end{array}$} & \multicolumn{2}{|c|}{ Total } \\
\hline & $N$ & $\%$ & $\mathrm{~N}$ & $\%$ & $\mathrm{~N}$ & $\%$ & $\mathrm{~N}$ & $\%$ & $N$ & $\%$ \\
\hline PTB & 6 & 100,0 & 0 & 0,0 & 0 & 0,0 & 0 & 0,0 & 6 & 100,0 \\
\hline DEM & 15 & 83,3 & 3 & 16,7 & 0 & 0,0 & 0 & 0,0 & 18 & 100,0 \\
\hline PR & 3 & 75,0 & 1 & 25,0 & 0 & 0,0 & 0 & 0,0 & 4 & 100,0 \\
\hline PSB & 10 & 71,4 & 2 & 14,3 & 2 & 14,3 & 0 & 0,0 & 14 & 100,0 \\
\hline PSDB & 25 & 71,4 & 6 & 17,1 & 4 & 11,4 & 0 & 0,0 & 35 & 100,0 \\
\hline “ppd” & 24 & 70,6 & 9 & 26,5 & 1 & 2,9 & 0 & 0,0 & 34 & 100,0 \\
\hline PP & 13 & 68,4 & 4 & 21,1 & 2 & 10,5 & 0 & 0,0 & 19 & 100,0 \\
\hline PPS & 14 & 56,0 & 9 & 36,0 & 2 & 8,0 & 0 & 0,0 & 25 & 100,0 \\
\hline PDT & 5 & 45,5 & 4 & 36,4 & 1 & 9,1 & 1 & 9,1 & 11 & 100,0 \\
\hline PMDB & 9 & 40,9 & 12 & 54,5 & 0 & 0,0 & 1 & 4,5 & 22 & 100,0 \\
\hline PV & 5 & 31,3 & 6 & 37,5 & 4 & 25 & 1 & 6,3 & 16 & 100,0 \\
\hline “ppe” & 5 & 21,7 & 11 & 47,8 & 6 & 25,4 & 1 & 5,0 & 23 & 100,0 \\
\hline $\mathrm{PT}$ & 8 & 15,1 & 33 & 62,3 & 10 & 18,9 & 3 & 3,8 & 53 & 100,0 \\
\hline Total & 142 & 50,7 & 100 & 35,7 & 33 & 11,8 & 5 & 1,8 & 280 & 100,0 \\
\hline
\end{tabular}

Fonte: Elaboração própria.

Assim como no caso da forma dos websites, verifica-se uma acentuada distribuição desigual entre as várias legendas partidárias. Partidos de direita tais como DEM (83,3\%), "ppd" (70,6\%), PR e PTB (100\%) apresentaram um percentual amplamente predominante de candidatos que enfatizam em suas campanhas seus atributos de transferir recursos ou executar obras para uma localidade específica, padrão que consideramos próximo de atividades de cunho clientelista a assistencialista. Segue-se um segundo grupo formado por legendas tais como PSB, PPS, PP, PSD, que também apresentaram tais características de forma predominante, porém, menos intensa do que os candidatos dos partidos anteriormente citados, com perfil acentuadamente clientelistas. Por fim, podemos observar um quarto grupo, formado por partidos tais como PDT, PMDB, PT e PV, nos quais a ênfase nesse tipo de políticas é menos intensa.

Assim, podemos afirmar que várias legendas partidárias são muito distintas entre si no tocante ao conteúdo substantivo das mensagens veiculadas nos respectivos websites. A relação entre o conteúdo enfatizado nos websites dos candidatos e a taxa de eleição pode ser visualizada na Tabela 9: 
BRAGA, S.; NICOLÁS, M. A.; BECHER, A. R. Clientelismo, internet e voto:...

Tabela 9

Candidatos a vereador: conteúdo do website versus taxa de eleição Eleições de municipais de 2008

\begin{tabular}{|l|c|c|c|c|c|c|}
\hline & \multicolumn{2}{|c|}{ Eleito } & \multicolumn{2}{c|}{ Não eleito } & \multicolumn{2}{c|}{ Total } \\
\cline { 2 - 7 } & $\mathrm{N}$ & $\%$ & $\mathrm{~N}$ & $\%$ & $\mathrm{~N}$ & $\%$ \\
\hline Transferência concentrada de recursos & 26 & 65,0 & 116 & 48,3 & 142 & 50,7 \\
\hline Propostas do partido e parlamento & 6 & 15,0 & 94 & 39,2 & 100 & 35,7 \\
\hline Vínculos com setores organizados & 8 & 20,0 & 25 & 10,4 & 33 & 11,8 \\
\hline Densidade programática e apelo simbólico & 0 & 0,0 & 5 & 2,1 & 5 & 1,8 \\
\hline Total & 40 & 100,0 & 240 & 100,0 & 280 & 100,0 \\
\hline
\end{tabular}

Fonte: Elaboração própria.

Podemos observar que há uma forte associação entre a taxa de eleição dos vereadores e um conteúdo mais orientado para a defesa de políticas particularistas ("pork barrel"). Assim, adiantando uma importante conclusão deste artigo, pode-se dizer que, embora a forma da campanha eleitoral organizada através do websites não esteja associada à possibilidade de eleição do político, seu conteúdo (ou seja, a ênfase das políticas de transferência de recurso para localidades e clientelas específicas) que, por sua vez, expressa determinadas estratégias de campanha, pode estar associado com maior probabilidade a estratégias bem sucedidas de eleição.

O cruzamento das informações sobre a forma e o conteúdo dos websites nos permite sistematizar evidências a partir das quais é possível analisar e exemplificar qualitativamente os principais tipos de websites verificados durante a pesquisa e confirmar ou refutar nossa hipótese central acerta de os websites dos candidatos servirem predominantemente como veículos de práticas clientelistas (Tabela 10):

Tabela 10

Candidato a vereador: forma versus conteúdo dos websites Eleições municipais de 2008

\begin{tabular}{|c|c|c|c|c|c|c|c|c|c|c|}
\hline & \multicolumn{2}{|c|}{$\begin{array}{l}\text { Outdoor virtual } \\
\text { personalizado }\end{array}$} & \multicolumn{2}{|c|}{$\begin{array}{c}\text { Outdoor } \\
\text { virtual } \\
\text { partidarizado }\end{array}$} & \multicolumn{2}{|c|}{$\begin{array}{l}\text { Gabinete } \\
\text { virtual }\end{array}$} & \multicolumn{2}{|c|}{$\begin{array}{c}\text { Comunicação } \\
\text { e interação }\end{array}$} & \multicolumn{2}{|c|}{ Total } \\
\hline & $\mathrm{N}$ & $\%$ & $\mathrm{~N}$ & $\%$ & $\mathrm{~N}$ & $\%$ & $\mathrm{~N}$ & $\%$ & $\mathrm{~N}$ & $\%$ \\
\hline $\begin{array}{l}\text { Transferência concentrada de } \\
\text { recursos }\end{array}$ & 131 & 46,8 & 5 & 1,8 & 0 & 0,0 & 6 & 2,1 & 142 & 50,7 \\
\hline Propostas parlamentares & 35 & 12,5 & 41 & 14,6 & 19 & 6,8 & 5 & 1,8 & 100 & 35,7 \\
\hline $\begin{array}{l}\text { Vínculos com setores } \\
\text { organizados }\end{array}$ & 5 & 1,8 & 2 & 0,7 & 8 & 2,9 & 18 & 6,4 & 33 & 11,8 \\
\hline $\begin{array}{l}\text { Densidade programática e } \\
\text { apelo simbólico }\end{array}$ & 0 & 0,0 & 0 & 0,0 & 0 & 0,0 & 5 & 1,8 & 5 & 1,8 \\
\hline & 171 & 61,1 & 48 & 17,1 & 27 & 9,6 & 34 & 12,1 & 280 & 100,0 \\
\hline
\end{tabular}

Fonte: Elaboração própria. 
A Tabela 10 sugere que, ao invés de servir predominantemente como instrumento de ampliação das possibilidades de "participação" dos cidadãos comuns ou de "interação" do político com seu representante, a internet serviu, predominantemente, nas eleições municipais brasileiras de 2008, para veicular práticas mais tradicionais de política, que reforçam os vínculos personalistas e clientelistas estabelecidos entre eleitor e representante. Isso será melhor exemplificado com a análise qualitativa de alguns websites "típicos" de cada uma destas categorias que empreendemos a seguir.

a) Outdoor virtual personalizado com ênfase em políticas particularistas ou promessas vagas de melhoria $(46,8 \%$ dos websites)

O primeiro e mais frequente tipo de website é aquele que serve como "outdoor virtual" dos políticos e onde a ênfase é posta em traços de sua personalidade e em seu relacionamento privilegiado com o chefe do executivo potencial ou no exercício do mandato, que o permitam executar obras de baixo impacto alocativo e de natureza particularista em coletividades específicas. Também são incluídos nessa rubrica os websites cuja ênfase é posta nos atributos pessoais do candidato e em sua capacidade de transferir benefícios ou recursos gerais para a "comunidade", através de políticas definidas de maneira vaga e não vinculadas a atividade concreta de nenhuma instituição, partido ou à ação de algum grupo de pressão específico. Alguns exemplos deste primeiro tipo de website são visualizados nas Figuras 1 e 2 :

Figura 1

\section{Candidato Tico Kuzma (PSDB/Curitiba/eleito)}

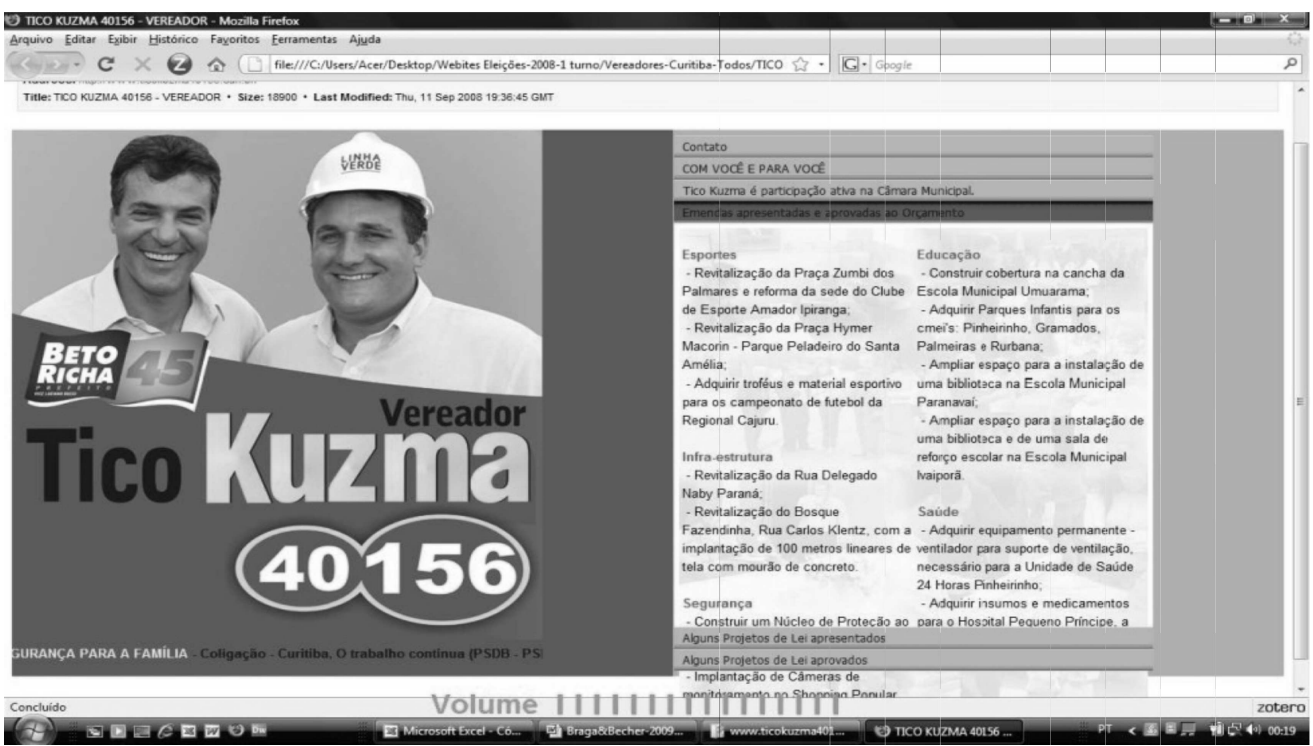


Figura 2

Dinho (PSB/Florianópolis/eleito)

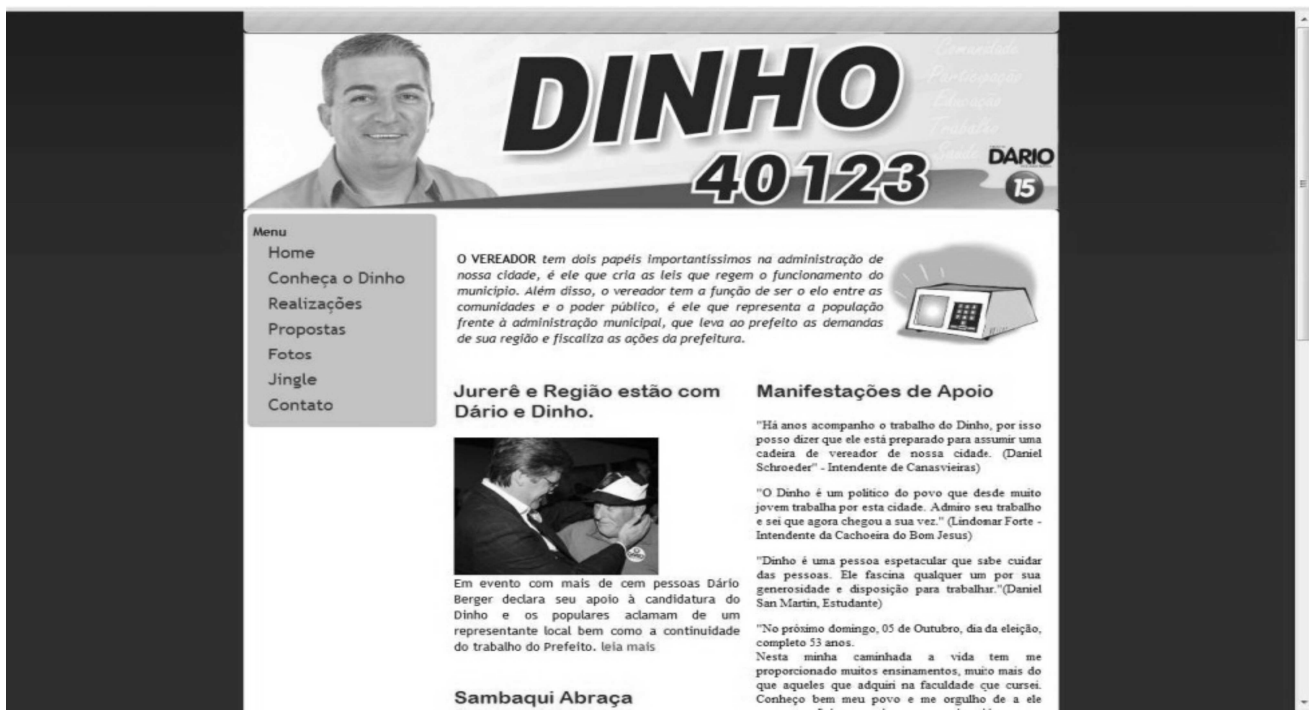

Alguns traços básicos do "outdoor virtual personalizado com ênfase para políticas locais, assistenciais ou particularistas" estão presentes nas Figuras 1 e 2: o pouco espaço dado ao partido e às políticas promovidas pelo partido nos websites, a ostentação da proximidade do vínculo com o chefe do executivo e com a administração pública de uma maneira geral e a listagem de várias obras e serviços a serem executadas caso o candidato seja eleito. Essas obras são, via de regra, de baixo impacto alocativo ou definidas de maneira vaga e genérica (as famosas "promessas" dos políticos) e seu sucesso depende em boa parte de uma posição favorecida do político ou do parlamentar com a administração pública, motivo pelo qual, geralmente, a defesa ou ostentação de tais propostas está associada a um silêncio ou omissão no tocante às políticas de maior impacto alocativo e apelo ideológico-programático. O candidato apresenta-se, assim, através de seu website, como um "despachante de luxo" (broken) destinado a agir como agente intermediário ou facilitador da obtenção de benefícios entre o eleitor e a administração pública.

b) Outdoor virtual partidário com ênfase em propostas parlamentares e mais gerais (14,6\%)

O segundo tipo de website mais frequente na campanha virtual dos candidatos a vereador nas cidades analisadas é o "outdoor partidário com ênfase nas atividades parlamentar e legislativa". Esse tipo de website é usado, geralmente, por dois tipos de candidatos: i) aqueles que pertencem a partidos mais institucionalizados ou cujas legendas partidárias possuem políticas mais proativas do uso da web em campanhas eleitorais; ii) aqueles parlamentares que já exerceram atividade parlamentar ou outros mandatos legislativos além da vereança. Esse tipo de website caracteriza-se também por possuir poucos recursos de comunicação e interação com o cidadão e ser focado na exibição e divulgação estática do candidato, mas abre mais espaço para a divulgação das propostas partidárias ou para a divulgação de propostas legislativas e relacionadas à atividade parlamentar, difundindo uma concepção de vereador 
além daquela predominante do político como sendo uma espécie de "despachante de luxo".

Este tipo de website é especialmente usado pelos candidatos aos quais os partidos fornecem "modelos (templates) de websites" mas não buscam fornecer maior densidade programática na divulgação de suas propostas. É o caso, por exemplo, dos websites da maior parte dos vereadores do PT e do PPS nas eleições de Curitiba, partidos que elaboraram "templates" para os candidatos divulgarem suas propostas, mas cujo conteúdo não enfatizava a identidade ou a linha partidária. Não possuem, portanto, uma definição programática ou simbólica mais definida (Figuras 3, 4 e 5):

Figura 3

Marron (PT/Curitiba)

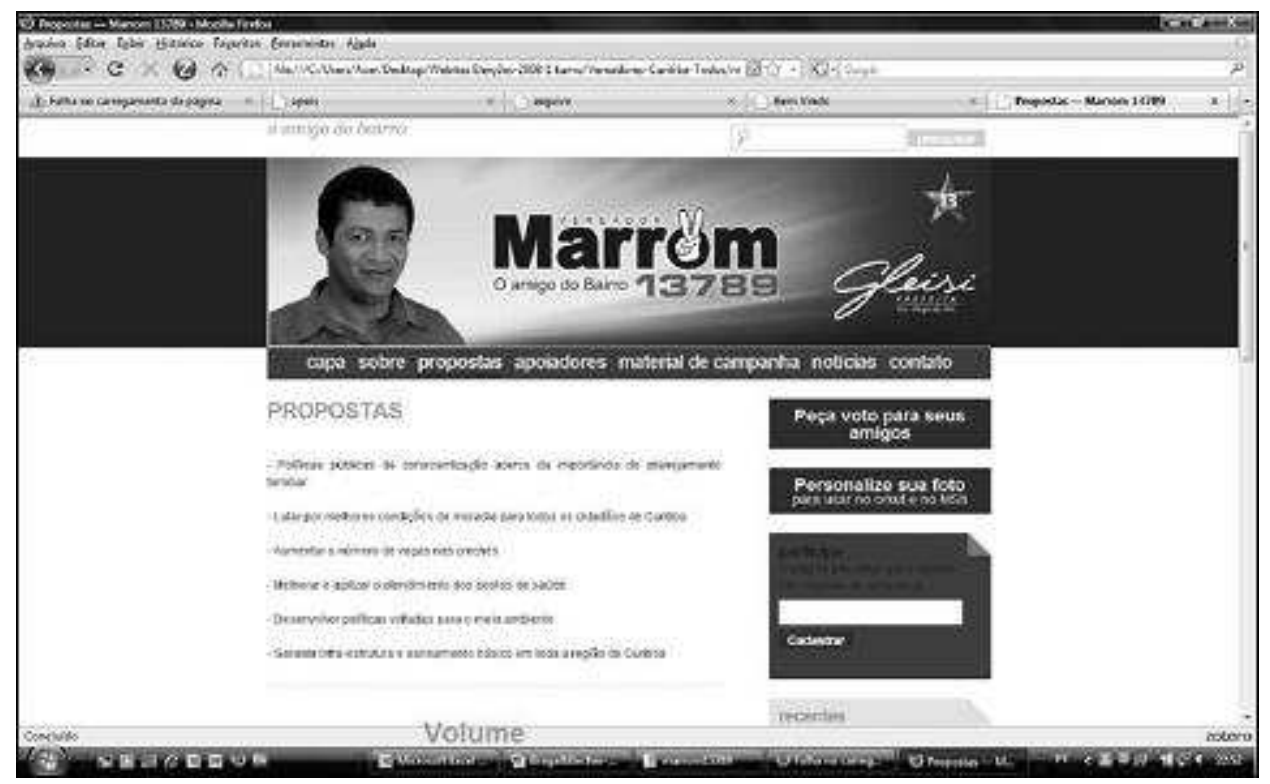


BRAGA, S.; NICOLÁS, M. A.; BECHER, A. R. Clientelismo, internet e voto:...

Figura 4

Adriana Mattos (PV/Florianópolis)

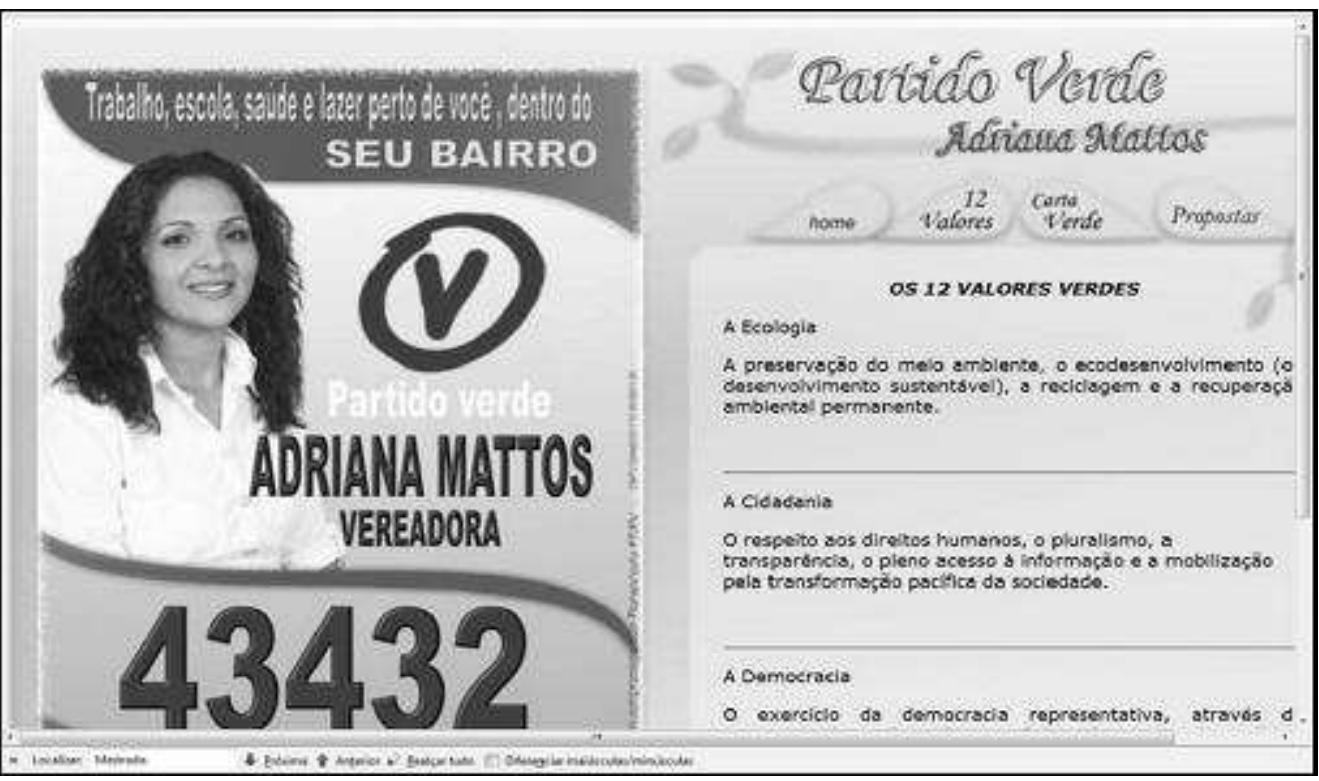

Figura 5

Chico (PT/Porto Alegre)

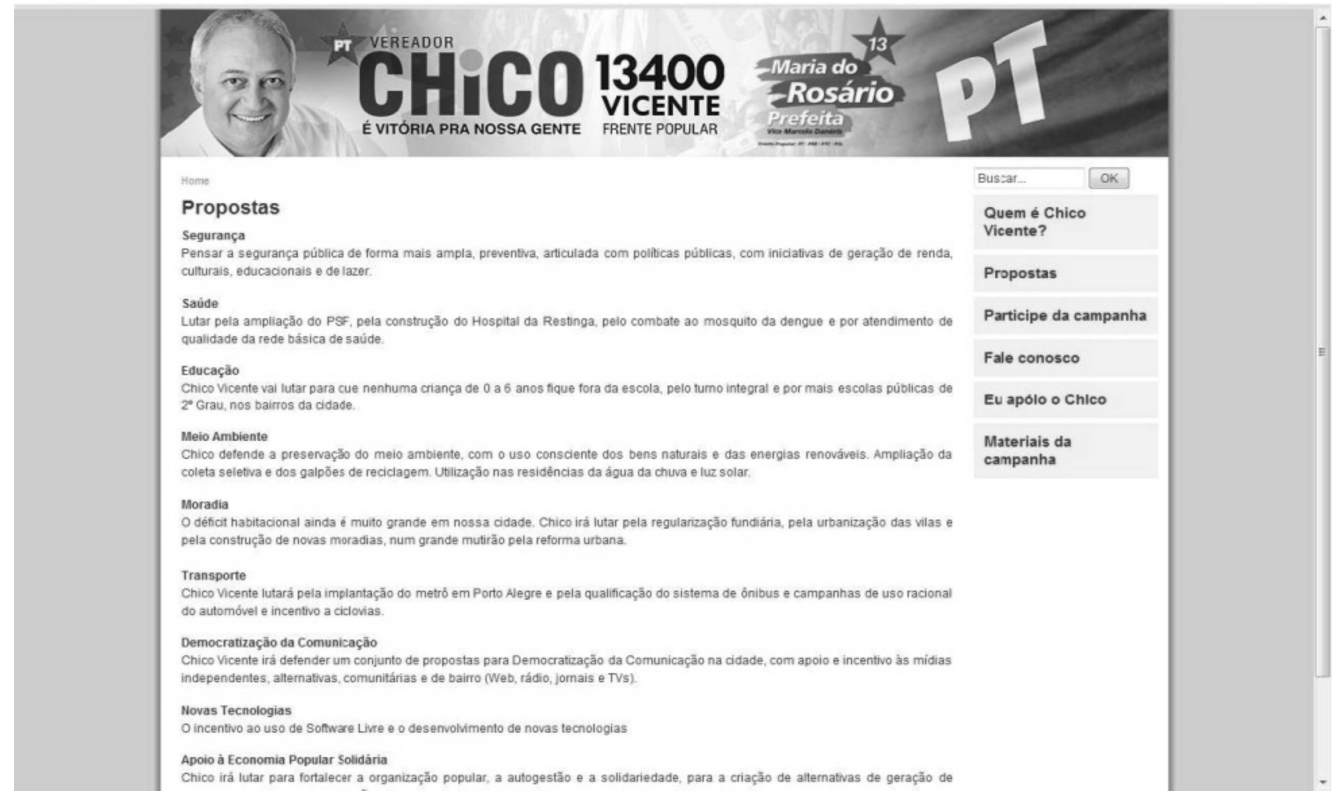


Esse tipo de website tende a dar maior espaço à legenda do partido e a propostas de natureza mais geral, mas sem vincular necessariamente a obtenção dessas metas ao fortalecimento da agremiação partidária, ou priorizar a agitação programática das propostas do partido.

c) Outdoor virtual personalizado e focado nas atividades parlamentares e em propostas mais gerais de policies $(12,5 \%)$

Um tipo frequente de website é aquele onde o parlamentar monta uma espécie de "gabinete" virtual para divulgar suas atividades pregressas no parlamento (geralmente, já no exercício do mandato do vereador), ou para esclarecer sobre o papel do vereador no parlamento ou sobre suas propostas parlamentares mais importantes. Entretanto, a menção à importância da atividade parlamentar não se mostra acompanhada do destaque na legenda partidária ou nas propostas programáticas do partido, nem na oferta ao potencial eleitor de maiores recursos ou ferramentas de interação e participação (por isso, vale lembrar, qualificamos este tipo de website de "outdoor virtual personalizado"). Alguns exemplos deste tipo de uso da internet para a realização de campanhas eleitorais nas eleições municipais de 2008 podem ser visualizados nas Figuras 6 e 7:

Figuras 6

\section{Acácio Garibaldi (PP/Florianópolis)}

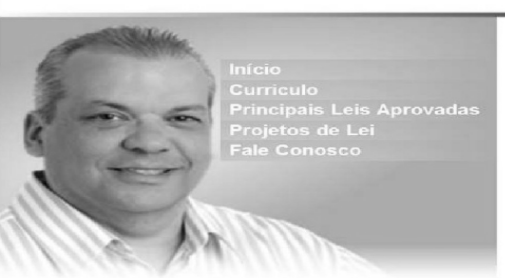

AGÁGIO GARIBALDI 11123 VEREADOR-PP

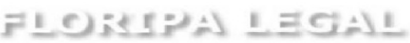

Principais Leis Aprovadas

Como vereador na legislatura dos anos de 2001 a 2004 , foi lider do governo e apresentou projetos importantes, que foram aprovados, como:

- lei que dispõe sobre o controle e destino dos óleos lubrificantes servidos:

- lei que dispōe sobre a divulgação dos valores arrecadados em multas de trânsito:

- lei que exclui a terceira casa decimal dos valores dos

- Iei que estabelece limites de gastos com cargos - lei que determina a contratação de deficientes pela AFLOV:

- lei que obriga supermercados e shoppings center a oferecer cadeiras de rodas para deficientes e idosos; - lei que assegura aos deficientes visuais a realização de provas de concursos públicos em braile; merenda diferenciada a criancas de ensino a fornecer hiprenda diferer - lei que conced para idosos em eventos desconto no valor da entrada de lazer;

- lei que faz obriga a reserva de cotas de participação aos deficientes nas feiras de arte e artesanato. 
Figura 7

Bernardino Vendruscolo (PMDB/Porto Alegre)

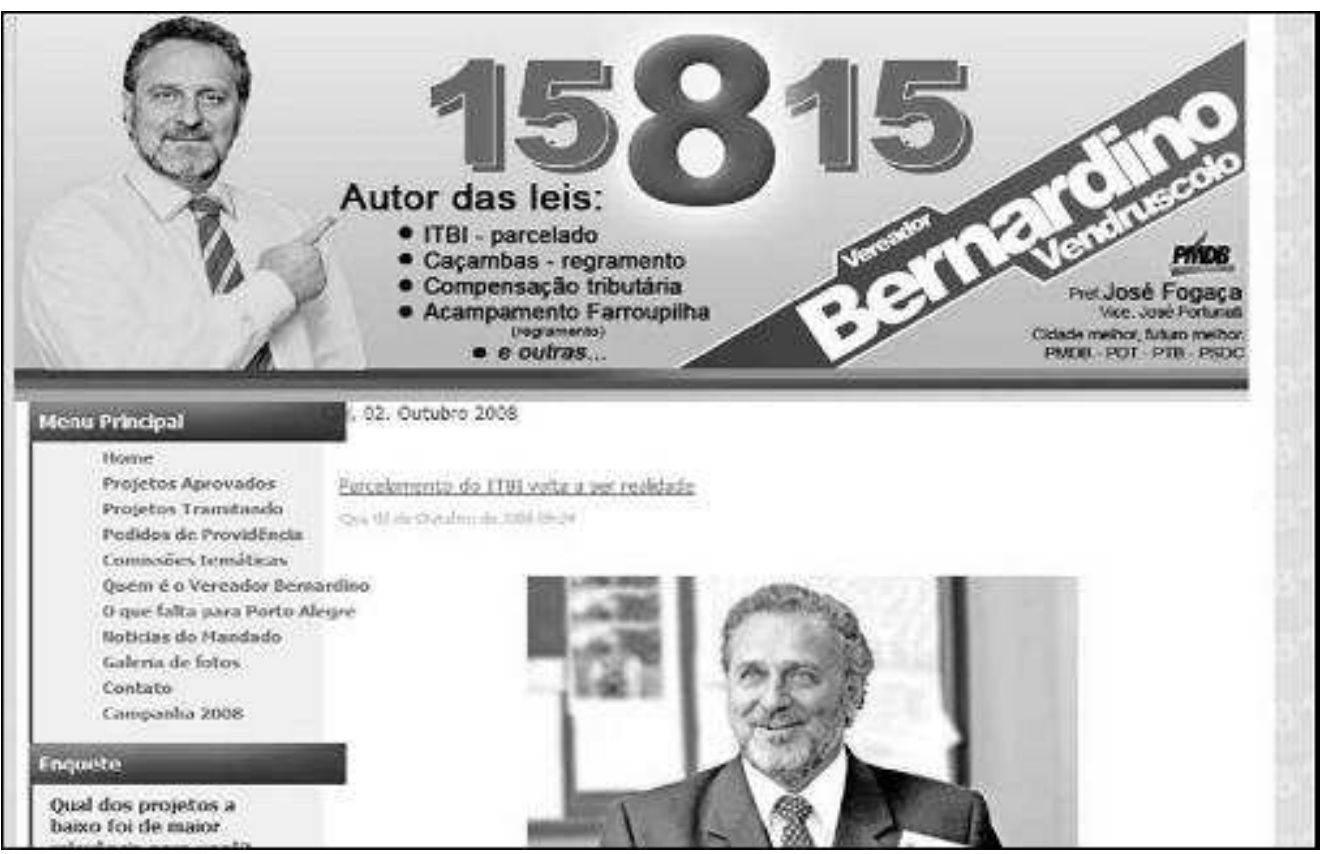

Nesses casos, o website funciona quase como um "gabinete virtual personalizado", com destaque para as atividades parlamentares passadas ou futuras do candidato.

d) Comunicação e informação com ênfase em propostas setoriais $(6,4 \%)$

Outro tipo de website apresenta recursos mais sofisticados de comunicação e interação com o eleitor, e utiliza tais recursos para divulgar e promover políticas de maior impacto alocativo voltadas para agrupamentos ou extratos sociais específicos, tais como GLS, ecologistas, desportistas, deficientes físicos, movimentos culturais alternativos (hip hop, rádios comunitárias etc.), e outras minorias desse tipo. Um exemplo pode ser visualizado na Figura 8: 
Figura 8

Célio Golin (PT/Porto Alegre)
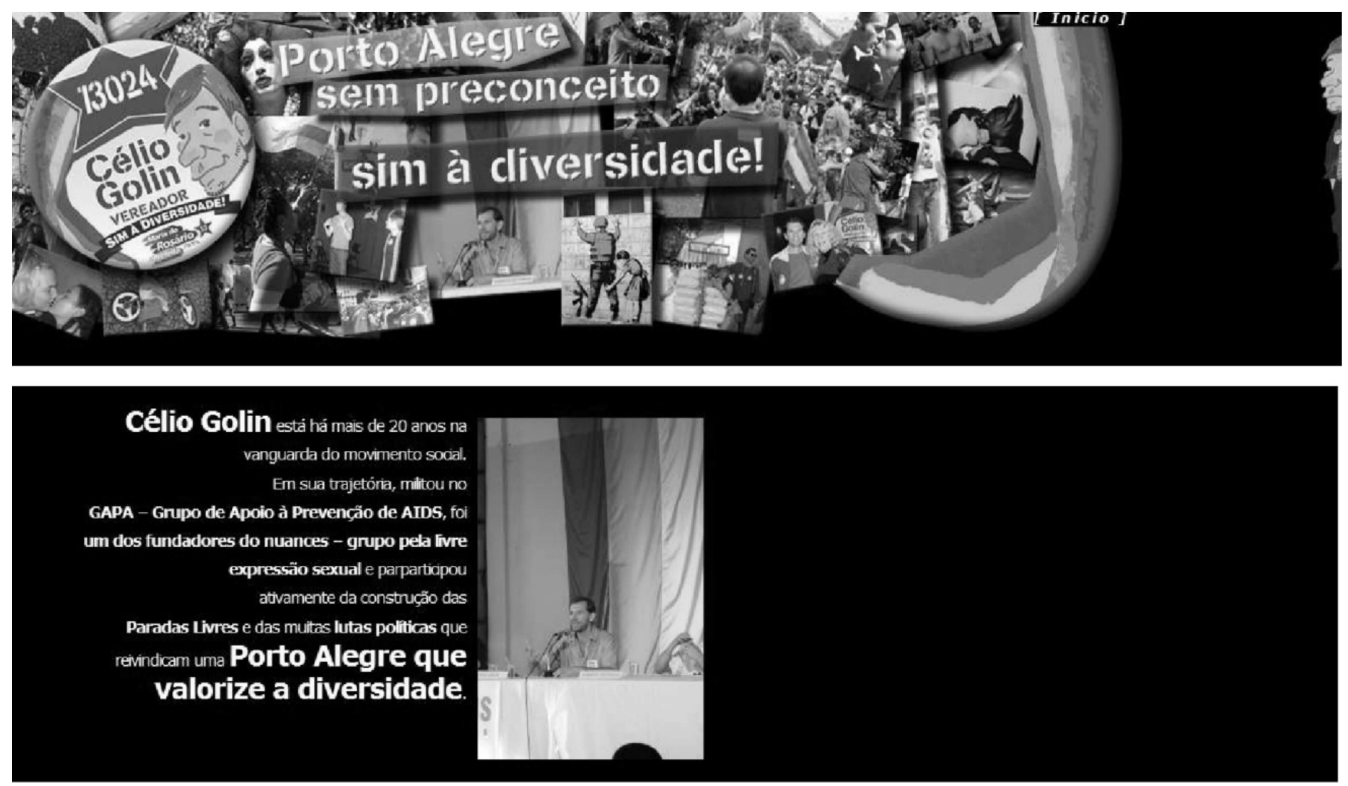

Este tipo de website, menos comum, utiliza recursos mais sofisticados de interação e comunicação (não exibidos na Figura 8) para promover políticas que beneficiam um grupo específico ou fortalecem a presença e a identidade simbólica de tal grupo.

e) Comunicação e informação com ênfase em propostas particularistas (2,1\%)

Este tipo de website (ainda menos frequente) é aquele que usa recursos mais modernos de comunicação e informação com os eleitores, mas cujo conteúdo de política é predominantemente local, enfatizando também a capacidade do político de transferir recursos para uma determinada localidade, a partir de uma boa relação com membros destacados da administração pública. A escassez de websites desse tipo pode ser explicada pelo fato de que candidatos que usam mais recursos de comunicação e informação tendem a divulgar políticas de apelo mais amplo, diversificando o conteúdo e a natureza das mensagens, o que dificulta a clara caracterização de políticas de natureza particularistas e/ou vagamente definidas, tais como mencionadas anteriormente. As Figuras 9 a 11 são alguns exemplos desta categoria de website de campanha: 
BRAGA, S.; NICOLÁS, M. A.; BECHER, A. R. Clientelismo, internet e voto:...

Figura 9

Geonísio Marinho (PSL/Curitiba)

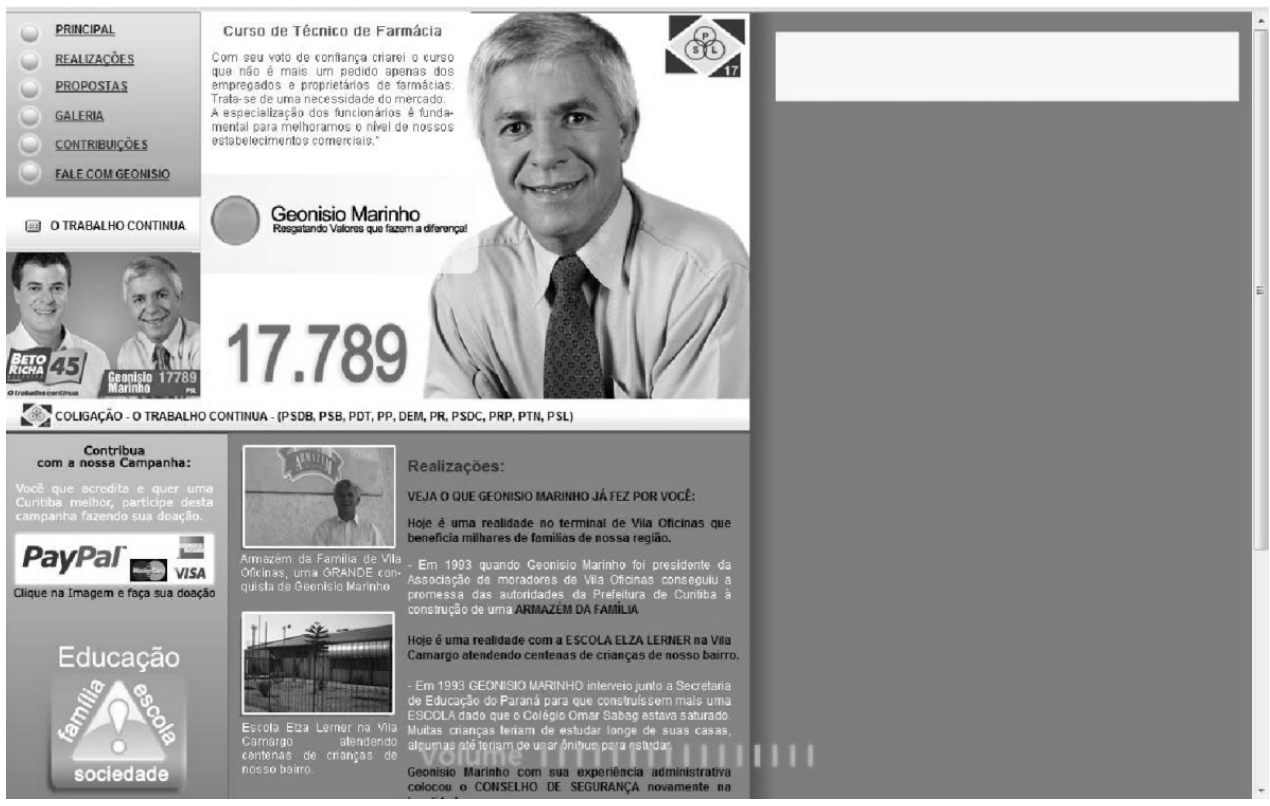

Figura 10

Aldaci Oliboni (PT/Porto Alegre)

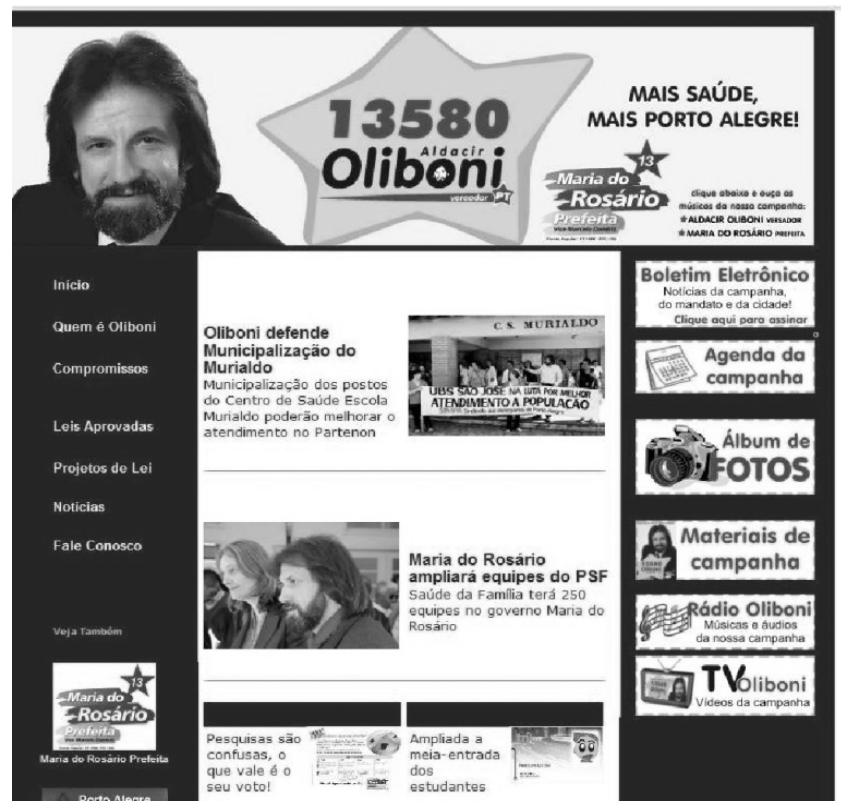


Figura 11

Jonny Stica (PT/Curitiba/eleito)

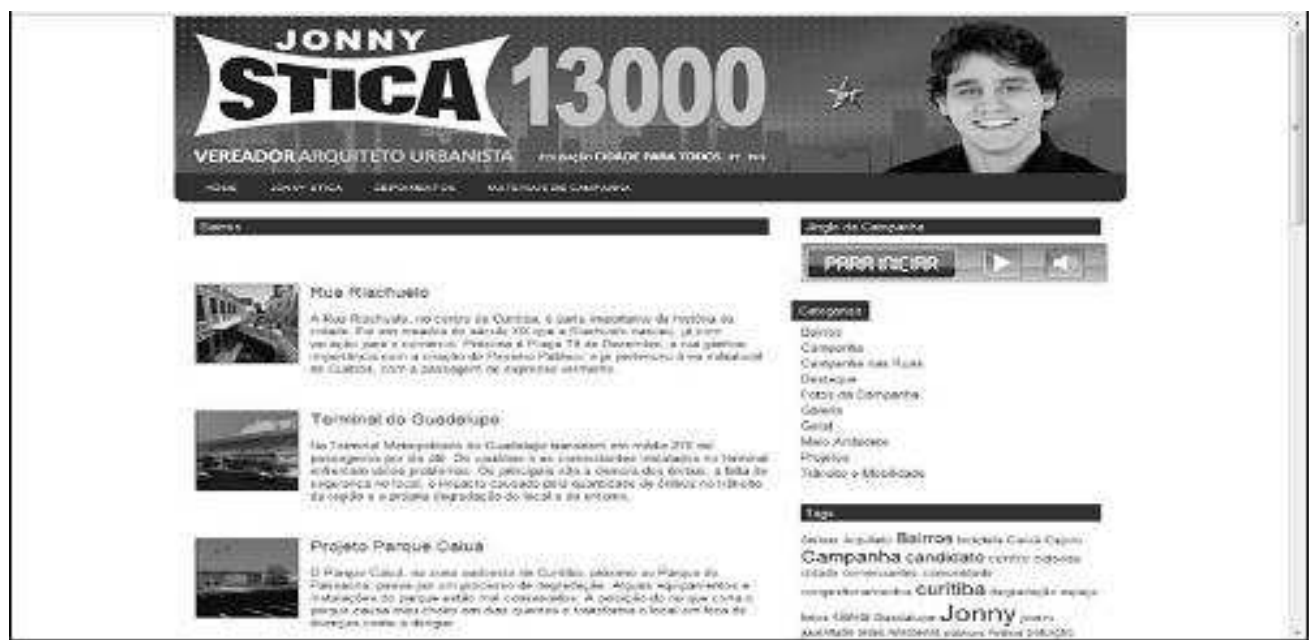

f) Comunicação e informação com ênfase na atividade parlamentar (1,8\%)

Um percentual ainda menor dos candidatos, no entanto, utiliza recursos mais sofisticados de comunicação e interação para divulgar sua atividade parlamentar, e não políticas focadas especificamente voltadas aos bairros. Via de regra, tais candidatos não foram muito bem-sucedidos do ponto de vista eleitoral, como vimos antes.

A Figura 12 traz um exemplo de candidato a vereador de Curitiba que não conseguiu reelegerse mas tornou-se secretário municipal após a posse do novo prefeito. Esse tipo de candidato possui uma expectativa mais otimista acerca dos impactos da internet na campanha eleitoral e uma visão mais "institucionalizada" da atividade político-parlamentar que, no entanto, nem sempre traz dividendos eleitorais.

Figura 12

Jorge Bernardi (PDT/Curitiba)

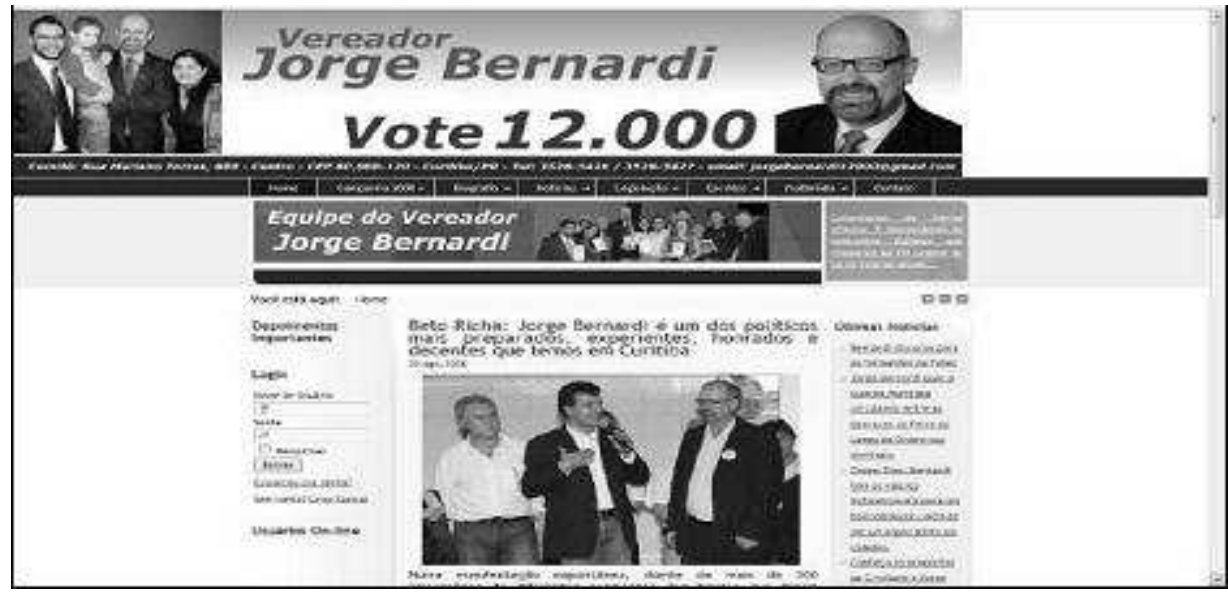


BRAGA, S.; NICOLÁS, M. A.; BECHER, A. R. Clientelismo, internet e voto:...

g) Comunicação e informação com grau mais elevado de politização $(1,8 \%)$

O último tipo de website, que também é exceção, busca usar recursos de comunicação e informação mais avançados (tais como newsletter, informações sobre organização de campanha, etc.) para difundir conteúdos de apelo ideológico mais geral (ou vínculos com lideranças personalistas de porte nacional) e perfil político ideológico-programático mais definido. As Figuras 13 e 14 exemplificam este tipo de website, cujo potencial de mobilização foi desconsiderado pelos candidatos a vereador na eleição de 2008 nas cidades analisadas:

Figura 13

Luiz Felipe (PSOL/Curitiba)

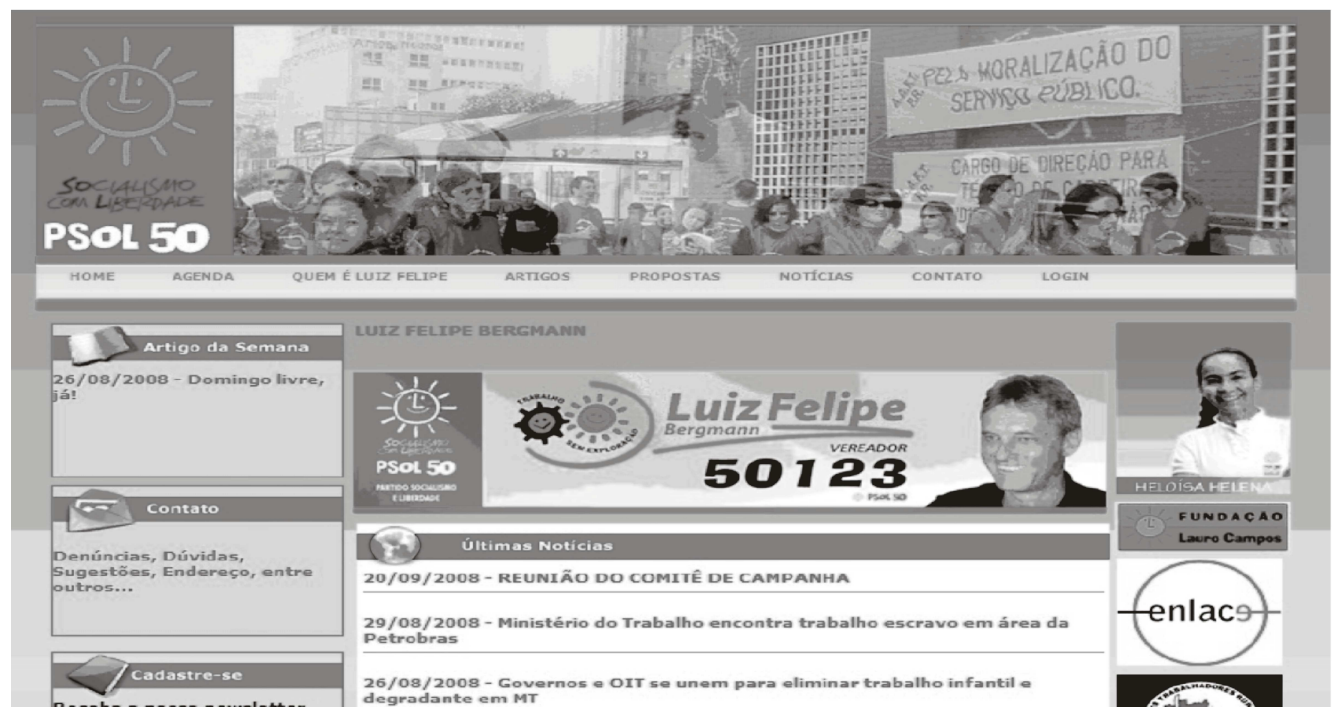

Figura 14

Ulisses Kaniak (PT/Curitiba)

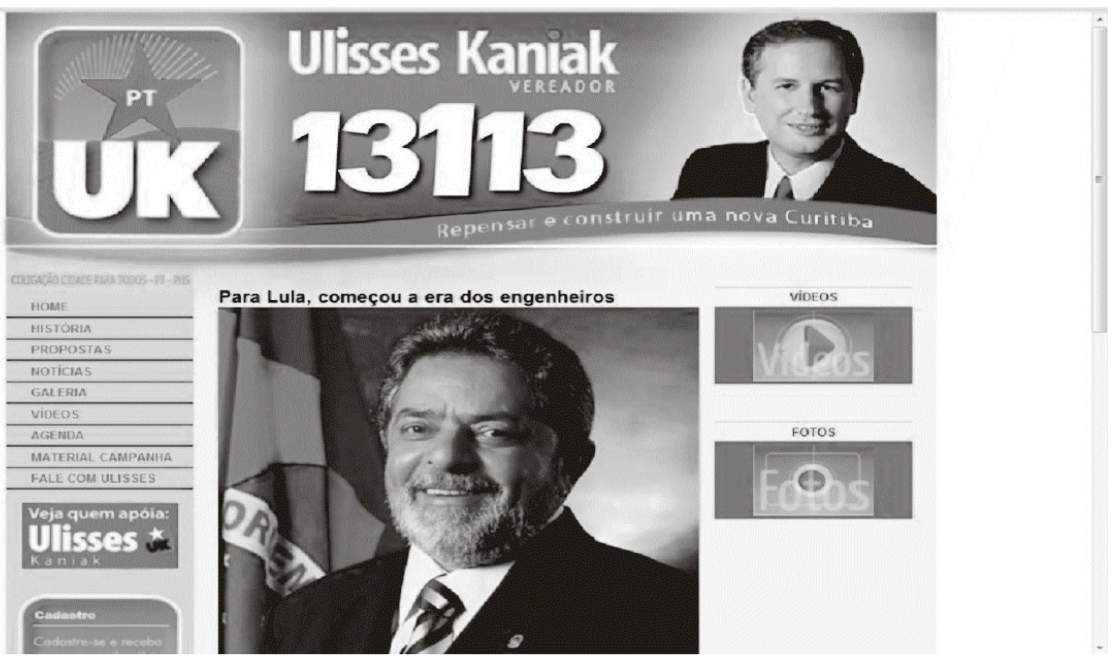


Observando estes websites, podemos verificar algumas características gerais que revelam uma maior preocupação em utilizar recursos mais sofisticados de comunicação e informação, inclusive esboçando o uso de alguns mecanismos de "interação e participação" mais sofisticados, tais como chats, contribuições financeiras, tentativas de organizar comitês de campanha e outros recursos desse gênero, para difundir políticas de perfil ideológico-programático mais definido ou mesmo para "nacionalizar" o pleito, associando-o a lideranças políticas de projeção nacional. Entretanto, constata-se também que, nos estágios atuais de consciência cívica do eleitorado brasileiro e de utilização das tecnologias virtuais pelos candidatos, tal estratégia de uso dos recursos virtuais ainda não tem trazido resultados eleitorais significativos aos candidatos, seja em termos de resultados de votos nas urnas, seja em termos de construção de imagem a longo prazo.

\section{Conclusões}

A fim de dar maior clareza e sistematicidade aos resultados do estudo exposto neste artigo, afastando-nos, assim, do estilo excessivamente especulativo e abstrato comum de ser encontrado na literatura sobre "internet, democracia e política", enunciamos de maneira sistemática alguns dos principais resultados provisórios de nossa investigação e enumeramos alguns pontos insuficientemente tratados que apontam para uma futura agenda de pesquisa mais aprofundada sobre a matéria.

Em primeiro lugar, ao contrário da expectativa que poderia ser gerada a partir da literatura sobre "internet e política" de viés excessivamente participacionista ou "deliberacionista", em 2008, ainda foi bastante escasso o uso da web pelos candidatos a vereador em Curitiba, Florianópolis e Porto Alegre, mesmo se avaliado pelos tacanhos parâmetros de possibilitar uma democracia representativa mais transparente e institucionalizada. Com efeito, excetuando o PT, o pequeno PRB e o PCdoB, o uso da web pelos partidos políticos nas eleições proporcionais no pleito de 2008 nas três cidades analisadas ainda foi bastante escasso. Apenas 360 dos 1493 candidatos ao cargo de vereador utilizaram websites de campanha durante o pleito, em contraste com as eleições majoritárias, onde a grande maioria dos candidatos a prefeito recorreu ao uso de websites ${ }^{15}$. Além disso, vimos que esse uso de websites foi desigualmente distribuído por partidos políticos: partidos de esquerda (PT e PCdoB) e de centro (PSDB e PPS), usaram mais websites do que partidos de direita (DEM e PTB). Observamos ainda que a maior parcela dos websites não foi usada como mecanismo de "interação, de participação ou para criar vias de deliberação com o cidadão-internauta", mas, sim, como "outdoors virtuais" dos candidatos a fim de exibir mecanismos "top down" de divulgação de suas propostas: quanto ao seu conteúdo, a maioria dos websites foi utilizada como mecanismo de divulgação e difusão de políticas mais localizadas e voltadas para a transferência de recursos e execução de obras e serviços em comunidades locais, em uma prática que, somada à ostentação da personalidade individual do candidato nos sites, podemos qualificar como "clientelista". Entretanto, não devemos inferir daí que o tipo de website "clientelista" (outdoor virtual personalizado com ênfase em políticas locais) tenha sido o tipo dominante entre todos os partidos. Como vimos, tais websites foram desigualmente distribuídos pelas diferentes legendas partidárias. Por fim, verificamos que os candidatos que investiram na divulgação de políticas locais e voltadas para determinados bairros e localidades tiveram uma maior taxa de sucesso nas eleições, em detrimento dos

\footnotetext{
${ }^{15}$ Cf. o levantamento efetuado por Braga, Nicolás e França (2010), que observa que, entre os 175 candidatos às prefeituras nas
} capitais brasileiras, 110 deles $(62,9 \%)$ usaram websites como recurso de campanha. 
BRAGA, S.; NICOLÁS, M. A.; BECHER, A. R. Clientelismo, internet e voto:...

candidatos que investiram na "politização" excessiva da campanha e na defesa de políticas programaticamente mais consistentes e de maior impacto alocativo.

Como problemas não resolvidos e uma agenda de pesquisa que deriva da análise apresentada destacam-se: i) A necessidade de refinar e tornar mais objetivos os critérios para análise de conteúdo dos websites, a fim de agregar novos elementos à análise de conteúdo além dos empregados neste artigo; ii) A necessidade de incorporar outras variáveis, além da filiação partidária e taxa de eleição, a fim de verificar se o uso diferenciado dos tipos de websites e de outras ferramentas virtuais pelos diferentes candidatos relaciona-se com outras variáveis tais como escolaridade, gastos de campanha, patrimônio e estrato social; iii) A necessidade de elaborar testes estatísticos mais sofisticados e modelos causais mais precisos, a fim de verificar os determinantes do uso diferencial dos websites por subgrupos de candidatos e; iv) Por fim, destaca-se a necessidade de aplicar mecanismos mais sofisticados de análise qualitativa de conteúdo de websites, a fim de relacionar as mensagens substantivas difundidas por este veículo com outras dimensões da atividade e do comportamento políticos dos atores observados.

Esses são alguns dos principais problemas de pesquisa que, a nosso ver, derivam da análise, bem como das evidências empíricas que coletamos e armazenamos durante a investigação sobre as eleições municipais brasileiras de outubro de 2008.

\section{Referências Bibliográficas}

AGGIO, C. "Campanhas Online: O percurso de formação das questões, problemas e configurações a partir da literatura produzida entre 1992 e 2009". Opinião Pública, Campinas, vol. 16, p. 426.445, 2010.

AmES, B. Os entraves da democracia no Brasil. Rio de Janeiro : Fundação Getúlio Vargas, 2003.

Avelino, G. "Clientelismo e política no Brasil. Revisitando velhos problemas". Novos Estudos. São Paulo, n 38, p. $225 \cdot 240,1994$.

BLANCHARD, G. "O uso da internet a serviço da comunicação do partido". Líbero, São Paulo, n 18, p. 9-17. dez. 2006.

BLONDEL, J. "The links between western european parties and their supporters. The role of personalization". Occasional Papers, $n^{\circ} 16 / 2005$.

Braga, S.; CruZ, L. C.; FrançA, A. S. T. "Como os políticos brasileiros estão usando a internet para se comunicar e interagir com o eleitor? Um estudo sobre o uso da internet pelos candidatos às eleições de outubro de 2006 na região sul do Brasil". Disponível em: <http://www. periodicos.ufsc.br/index.php/politica/article/view/1692/1435>. Politica \& Sociedade, vol. 6, p. 219.242, 2007.

BRAGA, S.; NicolÁs, M. A. "The parliament and the Internet: sociopolitical profile and use of the internet by the parliamentary elites of Argentina, Brazil, Paraguay, Uruguay, Venezuela and Chile". In: XXI IPSA World Congress of Political Science, 2009, Santiago. Anais do XXI IPSA World Congress of Political Science, 2009.

Braga, S.; NicolÁs, M. A.; FranÇA, A. S. T. "Uso da internet e oportunidades de participação política virtual nas eleições municipais de outubro de 2008 no Brasil". Revista Debates, Porto Alegre, vol. 5, p. 117-144, 2011.

Braga, S.; BeCher, A. "Personalização da política e novas tecnologias: balanço do debate e evidências sobre o Brasil". $36^{\circ}$ Encontro da Anpocs, Águas de Lindoia, 2012

Braga, S.; Nicolás, M. A.; BeCher, A. "Clientelismo, internet e voto: a campanha online dos candidatos a vereador no Brasil Meridional no pleito de outubro de 2008". Revista Compolítica, vol. 2, 2012.

BRAndÃo, F.; BATISTA, C. M. "Palanques virtuais: o uso de sites, e-mails e comunidades eletrônicas nas eleições de 2006. Paper apresentado no $6^{\circ}$ encontro da ABCP realizado em Campinas, 2008. 
CARvalho, J. M. "Mandonismo, coronelismo, clientelismo: uma discussão conceitual". Dados - Revista de Ciências Sociais, Rio de Janeiro, vol. 40, $\mathrm{n}^{\circ} 2,1997$.

DINIZ, E. Voto e máquina política: patronagem e clientelismo no Rio de Janeiro. Rio de Janeiro: Paz e Terra, 1982.

FARIAS, F. P. "Clientelismo e democracia capitalista: elementos para uma abordagem alternativa". Revista de Sociologia e Política, Curitiba, n²15, p. 49.66, nov. 2000.

FARIAS, F. P. "Clientelismo e democracia capitalista: elementos para uma abordagem alternativa". Revista de Sociologia e Política, Curitiba, n²15, p. 49-66, nov. 2000.

Fernandez, R. G. Campanhas Eleitorais Brasileiras na Internet. Dissertação de Mestrado apresentada ao Departamento de Ciência Política do Instituto de Filosofia e Ciências Humanas da Universidade Estadual de Campinas. Campinas, 2005.

Gomes, W.; AGGIO, C. "Campanhas on-line: o percurso de formação de questões, problemas e configurações a partir da literatura produzida entre 1992 e 2009". Curitiba: UPFR. Paper apresentado ao I Congresso de Pós-Graduação em Sociologia da UFPR, 2009

IASULAITIS, S. "Internet e propaganda política no Brasil: limites e possibilidades". Estudos de Sociologia, Araraquara, vol. $12, n^{\circ} 23$, p. $153 \cdot 172,2007$.

KARLSEN, R. "A platform for individualized campaign? Social media and parliamentary candidates in the 2009 Norwegian Election Campaing". Policy and Internet, vol. 3, n 4, 2011.

KARVONEN, L. The personalization of politics: a study of parliamenrary democracies. London: ECPR Press, 2010.

KUSCHNIR, K. et al. "Political clientelism in contemporary democracy: the case of Brasil in comparative and interdisciplinary perspective". Oxford: Digitado. Workshop held at the Centre for Brazilian Studies at the University of Oxford on the 18th February, 2005.

LILLEKER, D., G., JACKSON, N. A Interacting and Representing: can Web 2.0 enhance the roles of an MP?. Paper apresentado ao ECPR Joint Sessions; April 2009, workshop "Parlaments, parties and politicians in cyberspace". Lisboa, 2009.

"Microblogging, Constituency Service and Impression Management: UK MPs and the Use of Twitter", The Journal of Legislative Studies, vol.17, $\mathrm{n}^{\circ} 1, \mathrm{p} .86 \cdot 105,2011$.

MaINWARING, S, P. "Políticos, partidos e sistemas eleitorais. O Brasil numa perspectiva comparada". Novos Estudos Cebrap, 29, p. 34-58, 1991.

Mcallister, I. The personalization of politics. In: Dalton, R. \& Klingemann, H.D. Oxford Handbook of Political Behavior, 2006.

Mughan, A. Media and the presidentialization of parliamentary elections. London: Palgrave NORTON, 2000.

NicolÁs, M. A. Internet e política: graus de representação política e uso da internet pelas elites. Curitiba, Dissertação de Mestrado em Sociologia, UFPR, 2009.

NicolaU, J. M. "Como Controlar o Representante? Considerações sobre as Eleições para a Câmara dos Deputados no Brasil". Dados, Rio de Janeiro, vol. 45, n² 2, p. 219 a 236, 2002.

NORTON, P. "Four Models of Political Representation: British MPs and the Use of ICT". The Journal of Legislative Studies, vol. 13, $n^{\circ} 3$, September, p 354-369, 2007.

NoRRIS, P. Digital Divide: Civic Engagement, Information Poverty, and the Internet Worldwide. Cambridge: Cambridge University Press, 2001.

NUNES, E. A gramática política do Brasil: clientelismo e insulamento burocrático. Rio de Janeiro: Zahar, 1997.

OliveIRA, C.; TORRES, L. D.; NASCIMENTO, T. P. "Clientelismo, campanhas e facções nas eleições para prefeito no interior baiano nos tempos da internet". Caxambu/MG: Anpocs. Paper apresentado ao GT11, Democracia, comunicação política e eleições no $32^{\mathrm{a}}$ Encontro Nacional da Anpocs, 2008.

PoguntKe, T., \& WeBB, P. The presidentialization of politics in democratic societies. Oxford: Oxford University Press, 2005. 
BRAGA, S.; NICOLÁS, M. A.; BECHER, A. R. Clientelismo, internet e voto:...

SAntos, F. Teoria das decisões legislativas: microfundamentos do clientelismo político no Brasil. Rio de Janeiro. $138 \mathrm{f}$. Tese (Doutorado em Ciência Política) - IUPERJ/Instituto Universitário de Pesquisas do Rio de Janeiro, 1997.

Swanson, D.; Mancini, P. Politics, Media and Modern Democracy. An International Study of Innovations in Electoral Campaingn and Their Consequences. Westport, Connecticut: Praeger, 1996.

Veloso, G. R. Clientelismo: uma instituição brasileira. Brasília. Dissertação de Mestrado em Ciência Política - Instituto de Ciência Política, UnB/Universidade de Brasília, 2006.

WefFoRt, F. O populismo na política brasileira. São Paulo: Paz e Terra. 3 ed., 1993.

Sérgio Braga·sssbraga@gmail.com

Maria Alejandra Nicolás · alejandranicolas@gmail.com

André Roberto Becher · andrerbecher@gmail.com
Submetido à publicação em fevereiro de 2012. Versão final aprovada em fevereiro 2013. 